University of Nebraska - Lincoln

DigitalCommons@University of Nebraska - Lincoln

Publications, Agencies and Staff of the U.S.

Department of Commerce

U.S. Department of Commerce

2012

\title{
The effect of soil surface litter residue on energy and carbon fluxes in a deciduous forest
}

T.B. Wilson

Atmospheric Turbulence and Diffusion Division/NOAA, tim.wilson@noaa.gov

T.P. Meyers

Atmospheric Turbulence and Diffusion Division/NOAA

J. Kochendorfer

Atmospheric Turbulence and Diffusion Division/NOAA

M. C. Anderson

USDA-ARS, martha.anderson@ars.usda.gov

M. Heuer

Atmospheric Turbulence and Diffusion Division/NOAA

Follow this and additional works at: https://digitalcommons.unl.edu/usdeptcommercepub

Part of the Environmental Sciences Commons

Wilson, T.B.; Meyers, T.P.; Kochendorfer, J.; Anderson, M. C.; and Heuer, M., "The effect of soil surface litter residue on energy and carbon fluxes in a deciduous forest" (2012). Publications, Agencies and Staff of the U.S. Department of Commerce. 359.

https://digitalcommons.unl.edu/usdeptcommercepub/359

This Article is brought to you for free and open access by the U.S. Department of Commerce at DigitalCommons@University of Nebraska - Lincoln. It has been accepted for inclusion in Publications, Agencies and Staff of the U.S. Department of Commerce by an authorized administrator of DigitalCommons@University of Nebraska - Lincoln. 


\title{
The effect of soil surface litter residue on energy and carbon fluxes in a deciduous forest
}

\author{
T.B. Wilson ${ }^{\mathrm{a}, *}$, T.P. Meyers ${ }^{\mathrm{a}}$, J. Kochendorfer ${ }^{\mathrm{a}}$, M.C. Anderson $^{\mathrm{b}}$, M. Heuer ${ }^{\mathrm{a}}$ \\ ${ }^{a}$ Atmospheric Turbulence and Diffusion Division/NOAA, P.O. Box 2456, Oak Ridge, TN 37831, USA \\ ${ }^{\mathrm{b}}$ USDA-ARS Hydrology and Remote Sensing Laboratory, Beltsville, MD, USA
}

\section{A R T I C L E I N F O}

\section{Article history:}

Received 23 June 2011

Received in revised form 15 March 2012

Accepted 19 March 2012

\section{Keywords:}

Residues

LAI

Soil-vegetation-atmosphere system

Energy budget and carbon fluxes

\begin{abstract}
A B S T R A C T
The Atmosphere-Land Exchange Surface Energy (ALEX) balance model is an analytical formulation of the energy and mass transport within the soil and the vegetation canopy used for simulating energy, evapotranspiration, and $\mathrm{CO}_{2}$ fluxes in a wide range of vegetation environments. The objective of this study was to evaluate the ability of ALEX to simulate the effect of soil-surface leaf litter residue on soil heat conduction $(\mathrm{G})$, sensible heat $(\mathrm{H})$, evapotranspiration (ET) (or latent heat (LE) when expressed as rate of energy loss) and $\mathrm{CO}_{2}$ fluxes in a deciduous forest. The model was evaluated in a deciduous forest in Oak Ridge, Tennessee where about $550 \mathrm{~g} \mathrm{~m}^{-2}$ of dry weight of slow decomposing leaf litter is produced annually during the fall season. Incorporating an explicit formulation of water and energy exchanges within the residue layer in ALEX improved the performance of the model against eddy covariance and G measurements. The discrepancies between model simulations made with and without leaf litter residue were largest during the spring and fall, when soil contributions dominated the energy budget of the forest. During these periods, particularly during the spring, without the inclusion of the residue layer the model overpredicted LE, G, soil temperature and soil moisture, and underpredicted $\mathrm{H}$. The model showed no differences in simulating above-canopy net radiation ( $\mathrm{RN}$ ), with a slight difference in the above-canopy $\mathrm{CO}_{2}$ flux. The largest model improvement for residue effects was in the simulation of $\mathrm{G}$, with the slope of the regression line between predicted and measured values reduced from 2.28 for the model without residue effects to 1.07 when the residue effect was considered.
\end{abstract}

(ㄷ) 2012 Elsevier B.V. All rights reserved.

\section{Introduction}

Copious amounts of undecomposed leaf litter persist on the floor of deciduous forests in Tennesseee and across the south eastern United States (Hanson et al., 2003a). This heavy leaf litter residue affects all aspects of the energy balance, temperature, moisture, and $\mathrm{CO}_{2}$ flux processes in the forest environment (Caprio et al., 1985; Enz et al., 1988; Sauer et al., 1998; Shen and Tanner, 1990; Tanner and Shen, 1990; Aase and Siddoway, 1980; Aiken et al., 1997; Grant et al., 1995; Bussiere and Cellier, 1994; Wu et al., 1996). Accurate knowledge of the impact of the residue cover on the soil energy and water budgets is important in evaluating the energy, water, and $\mathrm{CO}_{2}$ budgets that are routinely monitored by flux tower networks in deciduous forest environments (Turnipseed et al., 2002; Oliphant et al., 2004; Arain et al., 2003). Models describing the soil-plant-atmosphere interactions represent the most attractive modeling framework to incorporate formulations for exchange processes of energy and mass within residue cover

\footnotetext{
* Corresponding author. Tel. +1 865576 1249; fax: +1 8655761327

E-mail address: tim.wilson@noaa.gov (T.B. Wilson).
}

below vegetation stands. Unlike empirical or statistical methods that need constant parameter calibrations, soil-plant-atmosphere models are process-based plant-environment models that attempt to explicitly formulate the important energy and mass exchange processes to provide a priori predictions of energy, water, and $\mathrm{CO}_{2}$ fluxes. Soil-plant-atmosphere models vary widely, and examples range from the simple bulk-canopy "big-leaf" types (Monteith, 1965; Priestley and Taylor, 1972), the intermediate two-source (soil+canopy) types with either single-layer or multi-layer soil profile (Shuttleworth and Wallace, 1985; Norman et al., 1995; Anderson et al., 2000, 2003), to detailed, multi-layer process models of the soil-plant-atmosphere system (Baldocchi and Wilson, 2001; Norman and Campbell, 1983; Dickinson et al., 1993). Despite significant progress in understanding soil-plant-atmosphere interactions, only a few models include explicit formulations of residue effects on the soil surface below growing vegetation.

Ogee and Brunet (2002) performed one of the few studies that evaluated how residue cover affects the microclimate below a vegetation canopy during the growing season. They added a heat and water leaf litter sub-model to a soil vegetation atmosphere transfer (SVAT) model and successfully predicted the soil and litter water 
content, soil and litter temperature, and fluxes of sensible heat, soil heat conduction, and latent heat below a pine forest in southwest France. However, they did not simulate fluxes of energy, water vapor, and $\mathrm{CO}_{2}$ above the canopy. El Maayar et al. (2001) found that adding a formulation of organic soil horizon atop a mineral soil layer in an Integrated Biosphere Simulator (IBIS) model greatly improved model performance in simulating fluxes of sensible heat $(\mathrm{H})$, soil heat conduction $(\mathrm{G})$, latent heat $(\mathrm{LE})$, and $\mathrm{CO}_{2}$ in both deciduous and conifer forests in the boreal forest region of Canada. A version of IBIS called Agro-IBIS (Kucharik and Brye, 2003) overpredicted energy budget components over the different seasons in corn and soybean fields in Mead, Nebraska, and this disagreement was attributed to the omission of residue formulation in the model (Kucharik and Twine, 2007). Other previous studies evaluated how residues affect surface turbulence, soil moisture, soil temperature, soil $\mathrm{CO}_{2}$ flux, and soil nutrients in addition to the surface energy components of radiation, sensible heat, evaporation, and soil heat flux (Sauer et al., 1996; Burgess et al., 2002; Baker et al., 2001). The quantification of residue properties has been conducted for modeling surface microclimate (Daughtry, 2001; Wagner-Riddle et al., 1996; Shen and Tanner, 1990), and several models aimed at simulating the effects of residues on the soil surface without the presence of growing vegetation are available (Enrique et al., 1999; Bristow et al., 1986; Gijsman et al., 2002; Bussiere and Cellier, 1994).

A two-source (canopy+soil) model known as the Atmosphere-Land Exchange Surface Energy (ALEX) balance model developed by Anderson et al. (2000) is used in this study to evaluate the benefits of explicitly including the formulations for residues atop the soil surface below the vegetation canopy. Anderson et al. developed ALEX as a simple, analytical model based on the bulk canopy resistance to canopy-atmosphere gas exchange formulated using canopy light-use efficiency (LUE), which is defined as the ratio of net canopy carbon assimilation to the photosynthetically active radiation absorbed (APAR) by the canopy. Motivation for formulating canopy resistance in terms of canopy LUE is that measurements of bulk canopy LUE are relatively well conserved for a given vegetation system and LUE relieves the burden of computation and detailed data needs (Gower et al., 1999). To predict energy, water and $\mathrm{CO}_{2}$ fluxes above the plant canopy and at the soil surface beneath the canopy, ALEX links equations of the canopy energy and mass exchange processes to equations of soil water transport and heat conduction so that integrative solutions partition water and heat fluxes between the canopy and the soil surface below the canopy. Of particular interest to this study is that ALEX estimates the sensible heat and water vapor fluxes at the soil surface based on a soil surface transfer coefficient that is a simple empirical function of wind speed, surface roughness, and the turbulence intensity and length-scale (Sauer and Norman, 1995). This simple transfer coefficient does not explicitly include the presence of heavy residue cover on the soil surface. This omission is largely because the residue layer is a relatively complicated structure of plant materials that are difficult to monitor in individual fields. Moreover, formulating the coupling of the residue layer between soil surface and the air layer below the canopy in a plant-environment model is a difficult challenge. Notwithstanding this challenge, effects of residues on the variability of energy, water, and $\mathrm{CO}_{2}$ fluxes must be considered to improve the performance of ALEX throughout the growing season in different vegetation environments.

The ALEX model has been used successfully to evaluate the microclimate observed in various forests, grasses, and crops in the United States and Canada (Anderson et al., 2000). Kongoli and Bland (2000) modified the soil routine in ALEX to simulate the observed long-term snow depth, accumulation, ablation and melt on agricultural fields in the Upper Midwestern United States, but they removed the effects of the vegetation. Houborg et al. (2009) recently evaluated the potential for ALEX to adopt a more detailed model of canopy photosynthesis and transpiration based on the photosynthesis-stomatal conductance for individual leaves, using formulations proposed by Collatz et al. (1991, 1992), Ball et al. (1987), and Farquhar et al. (1980), but they found no significant advantage over the canopy LUE scheme which is currently used in ALEX. So far these evaluations of ALEX have given less attention to the effects of the soil surface below the canopy, and instead have focused on climate and canopy characteristics as the key factors for predicting the carbon dioxide and energy exchange between the vegetation canopy and the atmosphere.

Our focus in this paper is to assess whether explicitly including a residue sub-model in the ALEX model benefits the model predictions of energy, water, and $\mathrm{CO}_{2}$ fluxes in deciduous forest environments from spring leaf emergence through the fall senescence. Detailed evaluations of residue properties and detailed investigations of the dynamic interactions within the residue cover are beyond the focus of this paper. Many previous field and modeling studies have conducted detailed investigations of the properties, characteristics, and dynamic interactions of residue cover over the soil surface. For example, analyses of field studies have improved our understanding of the wind speed and turbulent statistics within and above crop residues (Novak et al., 2000a), and the transfer of thermal radiation, sensible heat, latent heat and heat conduction within and beneath residues (Shen and Tanner, 1990; Tanner and Shen, 1990; Novak et al., 2000b). In addition, modeling studies have assessed the temperature and energy and water exchange within crop residue cover and have evaluated the impact of residue on soil temperature, latent heat, water content, and soil carbon and nitrogen dynamics (Bristow et al., 1986; Bussiere and Cellier, 1994; Findeling et al., 2007; Chung and Horton, 1987; Ferreira et al., 2003).

The objective of this paper is to modify the ALEX model by including in it the formulation of water and energy transport in a soil-residue-atmosphere system developed by Bristow et al. (1986), and to evaluate the modified ALEX model against the original ALEX model in simulating the climate in a deciduous forest environment. The purpose of the Bristow et al. model is to represent the dynamic interactions between the soil, residue, and the atmosphere to provide separate estimates of residue energy and water budgets that are coupled to the soil energy and water budgets. Results from the modified and unmodified ALEX models are compared to the measured soil heat conduction and eddy covariance measurements of water vapor, sensible heat, and $\mathrm{CO}_{2}$ fluxes over the forest across hours, days and years. This study (1) explores the relevance of using the modified-residue ALEX model during low leaf area index (LAI) conditions when the forest floor is exposed to high intensities of radiation, wind, and precipitation, and (2) identifies periods during the growing season when the non-residue ALEX model may be inadequate for predicting the microclimate conditions in forest environments.

\section{Methods}

\subsection{ALEX description}

The ALEX model is formulated as a soil-vegetation system analytical model that can combine dynamic interactions of multiple soil layers and a single vegetation canopy-air layer to determine the exchange of radiation, water vapor, sensible heat, and $\mathrm{CO}_{2}$ at the soil surface and above the plant canopy. The ALEX model is a simplified version of the mechanistic, multi-layer Cupid model which offers a more detailed formulation of vertical profiles of temperature and vapor pressure, and fluxes of radiation, sensible heat, water vapor, and $\mathrm{CO}_{2}$ throughout the soil-plant-atmosphere 
system (Norman and Campbell, 1983; Wilson et al., 2003; Norman, 1982). A detailed description of ALEX is found in Anderson et al. (2000). The number of soil layers is specified, along with the leaf area index (LAI) and canopy height, as well as the canopy turbulence roughness length and displacement height. The net radiation of the canopy layer and the photosynthetically active radiation absorbed (APAR) by the green fraction of LAI are calculated based on a simple analytical formulation of solar irradiance, LAI, leaf angle distribution (LAD), leaf absorptivity, and soil reflectance (Norman and Campbell, 1983). The use of APAR permits the calculation of the canopy stomatal resistance as a cubic function of wind speed, $\mathrm{CO}_{2}$ concentration, LAI and LUE (Anderson et al., 2000). The canopy $\mathrm{CO}_{2}$ flux or carbon uptake by photosynthesis (assimilation) is then calculated based on the canopy stomatal resistance. The canopy energy balance components are calculated as the combination of several factors, including differences in temperature and vapor pressure between the canopy and air layer above, net radiation, canopy stomatal resistance (estimated based on LUE), and canopy aerodynamic resistance (estimated based on the wind speed). To estimate the canopy sensible and latent heat fluxes, canopy temperature and vapor pressure are extrapolated by combining the equations of canopy-air temperature and vapor pressure with the canopy energy budget calculation. An iterative solution of these equations leads to estimated values of the canopy temperature and vapor pressure so that the sum of the latent and sensible heat fluxes is equal to the canopy net radiation.

The water vapor transport and heat conduction within the soil profile are obtained by solving second order, time-dependent, non-linear partial differential equations. The equation for the soil temperature $(T)$ and heat conduction $(G)$ is given by

$\rho_{s} C_{s} \frac{\partial T}{\partial t}=-\frac{\partial G}{\partial z}+Q$

where $\rho_{\mathrm{s}} C_{\mathrm{s}}$ is the volumetric soil heat capacity $\left(\mathrm{J} \mathrm{m}^{-3} \mathrm{~K}^{-1}\right), t$ is the time (s), $z$ is the soil depth $(\mathrm{m}), Q$ is the heat source calculated as $\left(R N_{\mathrm{S}}-L E_{\mathrm{S}}\right) / \nabla z\left(\mathrm{~W} \mathrm{~m}^{-3}\right) ; \mathrm{R} \mathrm{N} \mathrm{s}$ and $\mathrm{L} \mathrm{E} \mathrm{s}$ are the net radiation and latent energy at the soil surface and $\nabla z$ is the thickness of the soil surface layer ( $\mathrm{m})$. The $\mathrm{G}$ is derived by integrating Eq. (1) over the soil surface layer to obtain

$G=\rho_{s} C_{s} \nabla z \frac{\partial T}{\partial t}+K_{s} \frac{\partial T}{\partial z}$

where $K_{\mathrm{s}}$ is the soil thermal conductivity $\left(\mathrm{W} \mathrm{m}^{-1} \mathrm{~K}^{-1}\right)$. Similarly, the time rate of change of the soil water content is given by

$\rho_{w} \frac{\partial \theta}{\partial t}=-\frac{\partial}{\partial z}\left(K_{\mathrm{w}} \frac{\partial \psi}{\partial z}-K_{\mathrm{w}} g\right)-U$

where $\rho_{\mathrm{w}}$ is the density of water $\left(\mathrm{kg} \mathrm{m}^{-3}\right), \theta$ is the volumetric soil water content $\left(\mathrm{m}^{3} \mathrm{~m}^{-3}\right), K_{\mathrm{w}}$ is the soil hydraulic conductivity $\left(\mathrm{kg} \mathrm{s} \mathrm{m}^{-3}\right), \psi$ is the soil water potential $\left(\mathrm{J} \mathrm{kg}^{-1}\right), \mathrm{g}$ is the acceleration of gravity $\left(\mathrm{m} \mathrm{s}^{-2}\right)$, and $U$ is the volumetric soil water sink $\left(\mathrm{kg} \mathrm{m}^{-3}\right.$ $\left.\mathrm{s}^{-1}\right)$.

Eqs. (1) and (3) are solved as implicit finite difference equations using a Newton-Raphson procedure adopted from Campbell (1985). Solutions of the soil temperature and water profiles from Eqs. (1) and (3) are coupled with equations of the temperature and vapor pressure within the canopy air space. This coupling arrangement enables the energy balance components within the canopy air space and at the soil surface to be solved simultaneously using inputs of weather variables above the canopy and soil conditions at the lower boundary of the root depth in the soil; thus soil surface variables, including temperature, vapor pressure, surface latent and sensible heat are calculated rather than specified as input variables. The soil surface latent heat and the sensible heat fluxes are calculated from the respective gradients of soil surface temperature
Table 1

Parameters and values used in the temperate deciduous forest test of the ALEX model simulations.

\begin{tabular}{|c|c|c|}
\hline Parameters & Symbol & Value \\
\hline \multicolumn{3}{|l|}{ Site properties } \\
\hline Latitude, Longitude & Lat, Lon & $35^{\circ} 55^{\prime} 48^{\prime \prime}, 84^{\circ} 19^{\prime} 49^{\prime \prime}$ \\
\hline Elevation & $m$ & 336 \\
\hline Reference height & $z_{r}(\mathrm{~m})$ & 43 \\
\hline \multicolumn{3}{|l|}{ Canopy properties } \\
\hline Height of canopy top, base & $h(\mathrm{~m})$ & 26 \\
\hline LAI max, min & $L_{\max }, L_{\min }$ & $5.5,1.5$ \\
\hline Leaf length & $z_{1}(\mathrm{~m})$ & 0.06 \\
\hline $\begin{array}{l}\text { Fraction of range of green } \\
\text { vegetation }\end{array}$ & $f_{\text {gleaf }}$ & $0.1-1.0$ \\
\hline $\begin{array}{l}\text { Canopy roughness, displacement } \\
\text { height }\end{array}$ & $z_{0}, z_{d}(\mathrm{~m})$ & $0.07 \times h, 0.84 \times h$ \\
\hline Canopy light use efficiency (LUE) & $\beta$ & 0.012 \\
\hline $\begin{array}{l}\text { Nominal ratio of intercellular to } \\
\text { ambient } \mathrm{CO}_{2} \text { at } \beta=0.012, \beta=0\end{array}$ & $\gamma_{n}=C_{i} / C_{a}$ & $0.8,0.2$ \\
\hline $\begin{array}{l}\text { Green leaf absorptivity (visible, } \\
\text { near infrared, thermal) }\end{array}$ & VIS, NIR, TIR & $0.85,0.08,0.96$ \\
\hline $\begin{array}{l}\text { Dead leaf absorptivity (visible, } \\
\text { near infrared, thermal) }\end{array}$ & VIS, NIR, TIR & $0.55,0.35,0.96$ \\
\hline $\begin{array}{l}\text { Nominal maximum precipitation } \\
\text { interception by canopy }\end{array}$ & $w_{\max }(\mathrm{mm})$ & 0.15 \\
\hline $\begin{array}{l}\text { Nominal maximum fraction of } \\
\text { wetted LAI }\end{array}$ & $f_{\text {wetmax }}$ & 0.2 \\
\hline Rooting depth & $z_{\text {root }}(\mathrm{m})$ & 1.5 \\
\hline \multicolumn{3}{|l|}{ Soil properties } \\
\hline $\begin{array}{l}\text { Surface reflectivity of visible, } \\
\text { near-infrared, thermal emissivity }\end{array}$ & vis, NIR, $\varepsilon_{s}$ & $0.10,0.30,0.96$ \\
\hline Bulk density & $B D_{s}\left(\mathrm{~g} \mathrm{~kg}^{-3}\right)$ & 1.5 \\
\hline $\begin{array}{l}\text { Textural size fractions of sand, } \\
\text { silt, clay, quartz }\end{array}$ & & $0.25,0.55,0.20,0.20$ \\
\hline Air entry potential & $\psi_{e}\left(\mathrm{~J} \mathrm{~kg}^{-1}\right)$ & -3.3 \\
\hline $\begin{array}{l}\text { Moisture release curve } \\
\text { coefficient }\end{array}$ & $b_{x}$ & 6 \\
\hline Saturated hydraulic conductivity & $K_{s}\left(\mathrm{~kg} \mathrm{~s} \mathrm{~m}^{-3}\right)$ & $4.5 \times 10^{-4}$ \\
\hline \multicolumn{3}{|l|}{ Residue properties } \\
\hline Layer thickness & $z_{\text {residue }}(\mathrm{m})$ & 0.02 \\
\hline Residue bulk density & $B D_{r}\left(\mathrm{~kg} \mathrm{~m}^{-3}\right)$ & 45 \\
\hline Residue dry weight & $R D W\left(\mathrm{mg} \mathrm{ha}^{-1}\right)$ & 7.0 \\
\hline $\begin{array}{l}\text { The Bristow residue moisture } \\
\text { release curve }\end{array}$ & $b_{r}$ & 2.4 \\
\hline $\begin{array}{l}\text { The Bristow residue moisture } \\
\text { characteristic coefficient }\end{array}$ & $A_{r}\left(\mathrm{~J} \mathrm{~kg}^{-1}\right)$ & -350 \\
\hline $\begin{array}{l}\text { Nominal maximum water stored } \\
\text { within layer }\end{array}$ & $W R_{\max }\left(\mathrm{g} \mathrm{g}^{-1}\right)$ & 4 \\
\hline
\end{tabular}

and vapor pressure and the temperature and vapor pressure in the canopy air space using the soil surface water vapor and heat transfer coefficients (Sauer and Norman, 1995; Sauer et al., 1995).

\subsection{Equations of residue processes}

This section presents the modifications made to include the explicit formulation of residue processes in the ALEX model. Important modifications consisted of formulating equations of energy, water, and $\mathrm{CO}_{2}$ transport within the residues. Only the litter residue quantity was measured in this study; other residue characteristics, including properties of water and radiation transport within the residues were obtained from the literature (Table 1). Equations of the residue energy and water transfer processes were adopted from Bristow et al. (1986) and are summarized below. The residue heat conduction was calculated by solving Eq. (1) simultaneously for the residue layers and the soil layers, using only inputs of air temperature above the canopy and soil temperature at the lower boundary of the root zone. The transfer of water vapor within the residue 
was calculated based on the time rate of change of water within the residues (Bristow et al., 1986), given as

$$
\left(\frac{\rho_{a} \epsilon}{P}\right) \frac{\partial e}{\partial t}=\frac{\partial}{\partial z}\left(K_{\mathrm{v}} \frac{\partial e}{\partial z}\right)+U_{v}
$$

where $\rho_{a}$ is the density of air $\left(1.292 \mathrm{~kg} \mathrm{~m}^{-3}\right), \epsilon=0.622$ is the ratio of the molecular weights of water vapor $\left(18.02 \mathrm{~g} \mathrm{~mol}^{-1}\right)$ to dry air $\left(28.97 \mathrm{~g} \mathrm{~mol}^{-1}\right), P$ is the atmospheric pressure $(\mathrm{kPa}), e$ is the water vapor pressure ( $\mathrm{kPa}), K_{v}$ is the turbulence conductivity for water vapor $\left(\mathrm{kg} \mathrm{m}^{-1} \mathrm{~s}^{-1} \mathrm{kPa}^{-1}\right)$, and $U_{v}$ is the residue source-sink for evaporation or condensation $\left(\mathrm{kg} \mathrm{m}^{-3} \mathrm{~s}^{-1}\right)$. The $K_{v}$ is determined using an equation by (Norman and Campbell, 1983):

$K_{\mathrm{v}}=\frac{\epsilon K_{h}}{C_{\mathrm{p}} P}$

where $C_{p}$ is the specific heat of air $\left(29.3 \mathrm{~J} \mathrm{~mol}^{-1} \mathrm{~K}^{-1}\right)$ and $K_{h}$ is the turbulence conductivity for heat $\left(\mathrm{W} \mathrm{m}^{-2} \mathrm{~K}^{-1}\right)$ calculated as

$K_{\mathrm{h}}=\frac{\rho_{a} C_{p} D_{h}}{\Delta z}$

where $\Delta z$ is a specified residue layer depth (m) and $D_{h}$ is the turbulent diffusivity of heat transfer within the residue $\left(\mathrm{m}^{2} \mathrm{~s}^{-1}\right)$ calculated as

$D_{\mathrm{h}}=D_{h a}(1+0.007 T)(1+4 u)$

where $D_{h a}$ is the molecular diffusivity of heat transfer in air $\left(1.89 \times 10^{-5} \mathrm{~m}^{2} \mathrm{~s}^{-1}\right)$ at $0^{\circ} \mathrm{C}, T$ is temperature, and $u$ is the horizontal wind speed.

Similar to Eqs. (1) and (3), the solution of Eq. (4) in the various residue layers is obtained by using the Newton-Raphson finitedifference method as reported by Campbell (1985). The solution of the Newton-Raphson method is combined with empirically derived values of the water content and relative humidity $(\mathrm{h})$ within the residue layers, where values of the residue water content $\left(\theta_{r}\right)$ are estimated by (Bristow et al., 1986) as $\theta_{r}=0.064\left(h^{-0.51}-1\right)^{-0.42}$, and this iteration process leads to the derivation of residue vapor pressure values that balance with the change in the residue water content due to evaporation or rainfall interception. The upper boundary and lower boundary conditions used in solving Eq. (4) are the vapor pressure of the canopy air space and the water vapor pressure at the soil surface, respectively. The vapor pressure of the canopy air space is obtained from the solution of the canopy energy balance as described in Section 2.1, and the soil surface vapor pressure is calculated assuming equilibrium with the soil water potential at the soil surface.

The available net radiation within the residue layers is determined as the sum of the short wave solar radiation (SWR) and the long-wave thermal radiation (LWR) within the residue. The equation used to calculate the net SWR (NSWR) at a given layer $i$ in the residue was developed by Norman (1979) and reported by (Bristow et al., 1986), and given as

$N S W R_{i}=(1-t-r)\left[\left(1-t_{d}\right)\left(S_{d, i+1}+S_{d, u, i-1}\right)+\left(1-t_{b}\right) S_{b, i+1}\right]$

where $t$ and $r$ are the transmittance and reflectance of the individual residue elements, $t_{d}$ is the diffuse radiation transmittance of the residue layer, $t_{b}$ is the direct radiation transmittance of the residue layer, $S_{d}\left(\mathrm{~W} \mathrm{~m} \mathrm{~m}^{-2}\right)$ is the downwelling diffuse radiation, $S_{d, u}$ is the upwelling diffuse radiation, and $S_{b}\left(\mathrm{~W} \mathrm{~m}^{-2}\right)$ is the direct beam radiation. Using a formulation of LWR transfer within plant canopies (Norman, 1979), Bristow et al. (1986) calculated the net LWR at any given layer i within the residue that is divided into three layers:

$N L W R_{i}=a_{i} \sigma\left[t_{d, i+1} \epsilon_{a c} T_{a c}^{4}+\epsilon_{i+1} T_{i+1}^{4}+\epsilon_{i-1} T_{i-1}^{4}+t_{d, i-1} \epsilon_{s} T_{s}^{4}-2 T_{i}^{4}\right]$ where $a_{i}$ is the absorptivity of the residue layer, $\sigma$ is the StefanBoltzmann constant $\left(\mathrm{W} \mathrm{m}^{-2} \mathrm{~K}^{-1}\right), \epsilon_{a c}, \epsilon_{i}$, and $\epsilon_{s}$ are the emissivity values for the canopy air space, the residue layer, and the soil surface; $T_{a c}, T_{i}$, and $T_{s}$ are the temperature values of the canopy air space, the residue layer, and the soil surface; and $a_{i}=\epsilon_{i}$. Eqs. (8) and (9) are combined to get the available net radiation for a layer i as $R N_{i}=S W R_{i}+L W R_{i}$. The net energy balance above the surface of the residue is given by

$R N_{\mathrm{r}}=H_{r}+E_{r}+G$

where $H_{r}$ and $E_{r}$ are the latent heat and the sensible heat fluxes above the residue, and $\mathrm{G}$ is the heat conduction of the soil surface below the residue. Values of the vapor pressure $\left(e_{r}\right)$ from Eq. (4) and temperature $\left(T_{r}\right)$ from Eq. (1) at the top layer of the residue are combined with vapor pressure $\left(e_{a c}\right)$ and temperature $\left(T_{a c}\right)$ of the canopy air space to compute $H_{r}$ and $E_{r}$ as

$H_{\mathrm{r}}=\rho_{a} C_{p} \frac{T_{r}-T_{a c}}{R_{r}}$

$E_{\mathrm{r}}=\frac{\rho_{a} C_{p}}{\gamma} \frac{e_{r}-e_{a c}}{R_{r}}$

where $R_{r}$ is the turbulent resistance (1/eddy diffusivity) ( $\mathrm{s} \mathrm{m}^{-2}$ ) over the residue cover and $\gamma$ is the psychrometric constant $\left(0.067 \mathrm{kPa} \mathrm{K}^{-1}\right)$. Using the wind speed $\left(u_{s}\right)$ at the residue height, $R_{r}$ is estimated from an empirical function developedby Sauer et al. (1995) as,

$R_{\mathrm{r}}=\frac{1}{0.0035+0.011 * U_{S}}$

Another modification related to the soil-residue formulation in ALEX is the estimation of respiration from the residue layer as a component of the total respiration of $\mathrm{CO}_{2}$ from the ground. The traditional method for estimating soil respiration in ALEX used of the empirical equation by Norman et al. (1992) using values of LAI, and soil temperature and soil moisture in the top $0.1 \mathrm{~m}$ soil depth, which is suitable for bare soil surface conditions. The residue component of the surface respiration is calculated using an empirical equation that Hanson et al. (2003a) proposed to estimate leaf litter respiration below the deciduous forest reported in this study:

$R_{\text {resp }}=a b^{\phi} \beta^{\left(T_{r m}-20\right) / 10}$

where $R_{\text {resp }}$ is the respiration from the residue layer $\left(\mu \mathrm{mol} \mathrm{m} \mathrm{m}^{2} \mathrm{~s}^{-1}\right)$, $a$ is the litter-specific respiration at $20^{\circ} \mathrm{C}\left(0.0071 \mu \mathrm{mol} \mathrm{m}^{2} \mathrm{~s}^{-1}\right), b$ is a response constant for the litter residue maximum water potential (3.48), $\beta$ is the temperature response coefficient for a $10^{\circ} \mathrm{C}$ change in litter residue temperature (4.05), $T_{r m}$ is the mean temperature of the residue layer (C), and $\phi$ is the mean water potential of the residue layer (MPa), which is estimated as a function of the residue water content $(r w c)$ as $\left(\phi=-\left[5.53 * 10^{8} * 504.85^{\left((-3.22)(r w c)^{0.0528}\right)}\right]\right.$, where $r w c$ is the residue water content per oven dry weight $\left(\mathrm{g} \mathrm{g}^{-1}\right)$. To obtain the surface respiration rate, the calculation of the respiration rate from the residue is combined with the estimated component of the mineral soil (Norman et al., 1992), using values of the profiles of temperature and water derived from Eqs. (1)-(4).

\subsection{Model simulations}

Model simulations were divided into two runs in hourly time steps: one run was carried out using the original ALEX model that treats the soil surface as a bare rough/smooth surface overlying a soil profile with a specified number of arbitrary layers. The second run was conducted using the modified ALEX model with residue layers incorporated over the ground. Table 1 lists the basic input parameters used for the soil, residue, and forest canopy. The residue was divided into three layers of equal residue area index, and the 
Table 2

Statistics of the comparisons of measurements and modeled midday-average fluxes.

\begin{tabular}{|c|c|c|c|c|c|c|c|c|c|c|c|c|c|}
\hline \multirow[t]{2}{*}{ Flux } & \multirow[t]{2}{*}{ Unit } & \multirow[t]{2}{*}{ Year } & \multirow[t]{2}{*}{ No. days } & \multicolumn{5}{|c|}{ Modeled with residue } & \multicolumn{5}{|c|}{ Modeled without residue } \\
\hline & & & & Intercept & Slope & $R^{2}$ & Bias & RMSE & Intercept & Slope & $R^{2}$ & Bias & RMSE \\
\hline \multirow[t]{5}{*}{ RN } & \multirow[t]{5}{*}{$\mathrm{w} \mathrm{m}^{-2}$} & 2006 & 208 & -0.33 & 0.89 & 0.97 & 51.70 & 55.56 & -6.88 & 0.91 & 1.00 & 49.63 & 52.64 \\
\hline & & 2007 & 134 & -0.16 & 0.90 & 0.99 & 49.29 & 53.72 & -4.73 & 0.92 & 1.00 & 45.56 & 48.44 \\
\hline & & 2008 & 57 & -1.55 & 0.90 & 1.00 & 56.74 & 59.94 & -16.02 & 0.93 & 1.00 & 54.87 & 56.96 \\
\hline & & 2009 & 153 & -1.29 & 0.89 & 1.00 & 53.89 & 57.34 & -10.23 & 0.92 & 1.00 & 50.57 & 53.01 \\
\hline & & All years & 552 & -0.97 & 0.90 & 1.00 & 52.24 & 56.09 & -8.18 & 0.92 & 1.00 & 49.44 & 52.23 \\
\hline \multirow[t]{5}{*}{ G } & \multirow{5}{*}{$w m^{-2}$} & 2006 & 208 & 19.63 & 0.71 & 0.67 & -10.67 & 19.48 & 51.00 & 1.31 & 0.73 & -60.36 & 64.97 \\
\hline & & 2007 & 134 & 11.28 & 1.00 & 0.67 & -11.31 & 19.16 & 48.31 & 1.56 & 0.62 & -67.27 & 73.36 \\
\hline & & 2008 & 57 & 22.76 & 0.78 & 0.67 & -13.28 & 22.74 & 44.23 & 1.52 & 0.74 & -67.06 & 73.77 \\
\hline & & 2009 & 153 & 11.39 & 0.71 & 0.59 & 0.93 & 16.53 & 27.05 & 1.46 & 0.69 & -46.61 & 53.61 \\
\hline & & All years & 552 & 17.65 & 0.73 & 0.63 & -7.88 & 19.01 & 47.82 & 1.31 & 0.66 & -58.92 & 65.23 \\
\hline \multirow[t]{5}{*}{ LE } & \multirow[t]{5}{*}{$w m^{-2}$} & 2006 & 208 & -3.74 & 1.05 & 0.90 & -4.82 & 48.03 & 50.66 & 0.92 & 0.89 & -37.94 & 60.33 \\
\hline & & 2007 & 134 & -13.22 & 1.01 & 0.93 & 11.66 & 34.70 & 45.62 & 0.83 & 0.79 & -23.12 & 58.38 \\
\hline & & 2008 & 57 & -21.09 & 1.04 & 0.93 & 15.35 & 38.30 & 82.73 & 0.83 & 0.87 & -55.69 & 71.20 \\
\hline & & 2009 & 153 & -4.92 & 0.85 & 0.90 & 33.89 & 58.70 & 55.65 & 0.77 & 0.87 & -10.28 & 55.67 \\
\hline & & All years & 552 & -3.93 & 0.95 & 0.89 & 11.99 & 47.62 & 55.19 & 0.84 & 0.86 & -28.51 & 59.84 \\
\hline \multirow[t]{5}{*}{$\mathrm{H}$} & \multirow[t]{5}{*}{$w m^{-2}$} & 2006 & 208 & 78.04 & 0.95 & 0.75 & -69.64 & 93.71 & 61.84 & 0.55 & 0.65 & 8.79 & 59.02 \\
\hline & & 2007 & 134 & 127.27 & 0.73 & 0.76 & -70.07 & 97.40 & 99.61 & 0.46 & 0.63 & 16.41 & 78.63 \\
\hline & & 2008 & 57 & 122.19 & 0.82 & 0.88 & -85.63 & 102.77 & 91.31 & 0.39 & 0.62 & 35.84 & 98.55 \\
\hline & & 2009 & 153 & 126.62 & 0.75 & 0.72 & -90.63 & 115.42 & 89.63 & 0.39 & 0.56 & -3.18 & 78.96 \\
\hline & & All years & 552 & 109.19 & 0.81 & 0.77 & -77.99 & 101.95 & 80.18 & 0.48 & 0.65 & 10.12 & 74.46 \\
\hline \multirow[t]{5}{*}{$\mathrm{CF}$} & \multirow[t]{5}{*}{$\mu \mathrm{mol} \mathrm{m}^{-2} \mathrm{~s}^{-1}$} & 2006 & 208 & -3.69 & 0.73 & 0.83 & 1.00 & 4.59 & -3.33 & 0.66 & 0.82 & -0.02 & 4.54 \\
\hline & & 2007 & 134 & -3.55 & 0.72 & 0.83 & 2.03 & 4.26 & -3.13 & 0.67 & 0.81 & 1.37 & 4.06 \\
\hline & & 2008 & 57 & -3.70 & 0.70 & 0.83 & 0.91 & 4.24 & -3.77 & 0.62 & 0.87 & 0.25 & 4.46 \\
\hline & & 2009 & 153 & -3.23 & 0.66 & 0.79 & -0.36 & 5.20 & -3.22 & 0.55 & 0.78 & -1.53 & 5.56 \\
\hline & & All years & 552 & -3.57 & 0.70 & 0.83 & 0.86 & 4.66 & -3.33 & 0.62 & 0.82 & -0.07 & 4.73 \\
\hline
\end{tabular}

soil was divided into 12 arbitrary layers. An analytical formulation of the canopy reflectance and transmittance reported by Campbell and Norman (1998) was used to calculate radiation transfer within the canopy. The net radiation above and below the canopy was calculated based on the incoming and outgoing direct and diffuse components of the shortwave visible (VIS) and near infrared (NIR) radiation, and LWR using values of LAI, leaf angle distribution, leaf absorptivity in the VIS, NIR, and LWR, and soil reflectance in the VIS and NIR. Details of the net radiation calculation are available in Anderson et al. (2000). Within the residue, the transfer of direct and diffuse VIS and NIR radiation was calculated as a function of transmittance and reflectance of the residue layers and reflectance of the soil surface. Equations for the residue transmittance and reflectance developed by Norman (1979) were combined with Eq. (8) to calculate the SWR transport within the residue. Eq. (9) was used to calculate the LWR transfer within the residue layers from estimated values of emissivity, transmittance, and temperature of the canopy air layer, residue layers, and soil surface. Heat transport within the residue was determined by extending the solution of Eq. (1) to the residue layers. A finite difference equation of water vapor pressure was used to describe water vapor transport within the residue layers above the soil surface, which was then coupled to the soil water solution by Eq. (3). The eddy diffusivity for the heat and water vapor transfer within the residue was estimated from a linear wind profile equation by Bristow et al. (1986), using wind speed and residue temperature. Because of the lack of detailed information on the leaf litter elements below the forest, residue physical properties for radiation and water transport were obtained from the literature (Bristow et al., 1986; Shen and Tanner, 1990; Sauer et al., 1996; Sauer and Norman, 1995). In addition, the fraction of rainfall intercepted by residue layers was calculated as an exponential function of the cumulative area index from the top of the residue, and the residue water storage was estimated based on the residue density as proposed by Bristow et al. (1986). The residue was treated as a porous medium that was assumed to intercept rainfall until it reaches saturation. Starting at the residue top, when a layer was saturated, any intercepted rainfall was allowed to drain through to the next layer; and the amount of rainfall that was not intercepted by the residue was transmitted as input to the soil.

\subsection{Field measurements}

Field measurements to evaluate model predictions were obtained from the NOAA Surface Energy Balance Network (SEBN) flux tower in the national deciduous forest reservation in Oak Ridge, eastern Tennessee. The flux tower is a $60-\mathrm{m}$ walk-up tower located on a ridge, called Chestnut Ridge $\left(35^{\circ} 55^{\prime} 48^{\prime \prime} \mathrm{N}, 84^{\circ} 19^{\prime} 49^{\prime \prime} \mathrm{W}\right)$ that has been operating since 2005 , and it represents a continuation of the 30-m tall Walker Branch tower that dates back to 1997 (35 57' $\left.36^{\prime \prime} \mathrm{N}, 84^{\circ} 17^{\prime} 24^{\prime \prime} \mathrm{W}\right)$. This site is one of the longest operating flux towers providing continuous, long-term measurements of energy and carbon fluxes in forest environments using the eddy covariance flux measurement approach (Wilson and Meyers, 2001; Baldocchi et al., 1986; Wilson et al., 2001; Anderson et al., 2000). Both towers are located on a northeast-southwest ridgetop about $335 \mathrm{~m}$ above sea level with a gentle northwest-southeast slope $<10 \%$. The deciduous forest is dominated by oak, maple, poplar, and hickory species. The basal area of the forest stand is about $29 \mathrm{~m}^{2} \mathrm{ha}^{-1}$. The average height of the forest canopy top is about $26 \mathrm{~m}$. The silhouette woody biomass index and the peak LAI are about 1 and 6 , respectively. The LAI was estimated as a function of in situ-derived normalized difference vegetation index (NDVI) from measurements of radiation fluxes above the forest (Wilson and Meyers, 2007). The active growing season of the forest is characterized by periods of bud break in early April (DOY 90-110), peak LAI at the end of May (DOY 150), and senescence and abscission from early October to the end of November (DOY 280-330).

The understory of the forest stand is sparsely covered with small trees, shrubs and herbs on a forest floor that is covered with a large quantity of litter residue nearly shielding the soil surface below (Fig. 1). Soils at the site are Typic Paleudults formed in alluvium outwash of upland soils derived from rocks of dolomite, sandstone, and shale. Highly weathered, rocky, well-drained, and very deep $(>10 \mathrm{~m})$, the soil textures are predominantly silty clay loam with 


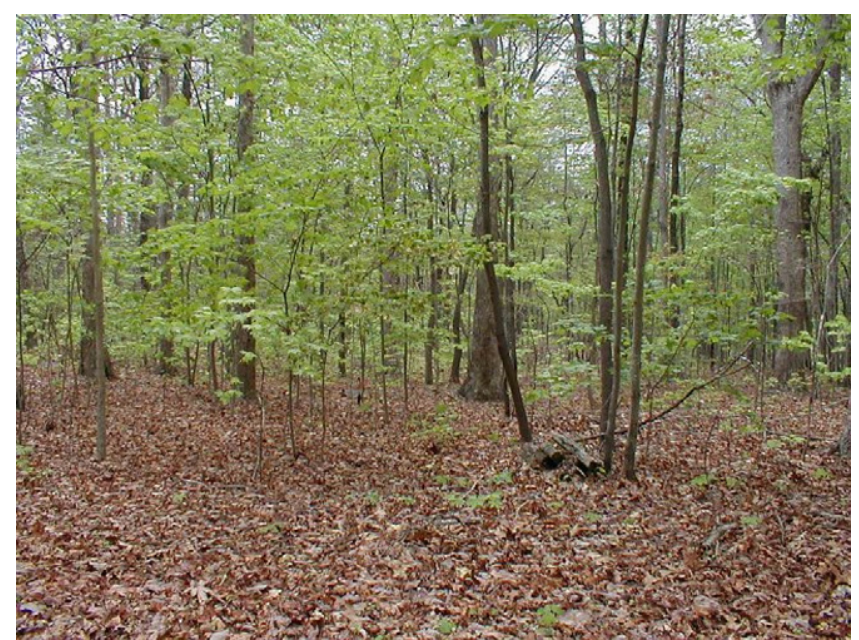

Fig. 1. Mid spring canopy growth with litter-covered forest floor below the deciduous oak forest, Chestnut Ridge, Oak Ridge, TN.

a yellow-red hue. The average bulk density of the soil horizon in the top $0.5 \mathrm{~m}$ is about $1.5 \mathrm{mg} \mathrm{m}^{-3}$. Climate records from 1981 to 2010 indicate that the site normally receives about $1300 \mathrm{~mm}$ of annual precipitation; the greatest normal monthly precipitation of about $130 \mathrm{~mm}$ occurs during the winter and early spring, while normal of about 116 and $100 \mathrm{~mm}$ occur the during summer and fall, respectively. The predominant wind direction at the site is out of the south-southwest, and the critical source of moisture for the area is the Gulf of Mexico. The normal monthly temperature at the site varies from about $5{ }^{\circ} \mathrm{C}$ during the winter and early spring to peak values of about $23^{\circ} \mathrm{C}$ during the summer, and then gradually decreases again to about $15^{\circ} \mathrm{C}$ during the fall.

\subsection{Eddy covariance flux measurements}

Eddy covariance measurements of latent heat (LE) and sensible heat $(\mathrm{H})$, and $\mathrm{CO}_{2}$ fluxes over the forest canopy were used to evaluate model predictions. Measurements consisted of 30-min averages and the dataset consisted of continuous measurements obtained during the growing season from DOY 100-300 in 2006-2009. Spurious measurements and missing data were eliminated from the evaluation and no gap filling was performed on the dataset. Sensors for the eddy covariance flux measurements were mounted at a height of $43 \mathrm{~m}$ on a walk-up scaffold tower, with the sensors about $17 \mathrm{~m}$ above the forest canopy. For the sensible heat flux, vertical wind velocity and air temperature fluctuations were measured with a three-dimensional ultrasonic anemometer (RM Young model 81000, R.M. Young Company, Traverse City, MI). For the LE and $\mathrm{CO}_{2}$ fluxes, water vapor and $\mathrm{CO}_{2}$ fluctuations were measured with an open path, infrared $\mathrm{CO}_{2} / \mathrm{H}_{2} \mathrm{O}$ gas analyzer ( $\mathrm{LI}-7500$, LI-COR, Lincoln, NE). Instantaneous values were sampled at a frequency of $10 \mathrm{~Hz}$ using a computer. Post-processing of the instantaneous data was performed offline, and computer software developed inhouse was used to correct for problems such as density fluctuations (Webb et al., 1980) to calculate the 30-min averages of the vertical fluxes of sensible heat, water vapor, and $\mathrm{CO}_{2}$ as the covariances of the vertical velocity and the corresponding scalar values of air temperature, water vapor and $\mathrm{CO}_{2}$. The sensible heat flux was calculated from the instantaneous fluctuations of the vertical velocity and the air temperature. LE and the $\mathrm{CO}_{2}$ fluxes were calculated using a lag time of $0.2 \mathrm{~s}$. for the vertical velocity to correct for the delay in the response of the $\mathrm{CO}_{2} / \mathrm{H}_{2} \mathrm{O}$ gas analyzer.

\subsection{Supporting measurements}

Supporting measurements collected above the forest at the same height as the eddy covariance measurements included downwelling and upwelling solar and thermal radiation measured with a net radiometer (CNR-1 Kipp \& Zonen, Delft, The Netherlands); downwelling and upwelling photosynthetically active radiation (PAR) measured using quantum sensors (Apogee Instruments, Inc., Logan, UT); air temperature and humidity measured with a Vaisala Humitter (model 50Y, Vaisala Oyj, Helsinki, Finland); air temperature measured with platinum resistance thermometer (PRT) (model RTDs, Thermometrics Corp., Northridge, CA); wind speed and direction measured with a wind vane anemometer (model 05103, R.M. Young, Traverse City, MI); precipitation measured with a tipping bucket raingauge (model TB3, Hydrological Services Pty Ltd, Liverpool, Australia); and atmospheric pressure measured with a pressure sensor (model PTB101B; Vaisala Oyj, Helsinki, Finland). The radiation sensors were mounted at the end of a 4-m long aluminum boom extended horizontally to the south of the tower. Upwelling and downwelling solar and thermal radiation from the net radiometer were used to calculate net radiation.

In addition to measurements above the canopy, soil conditions were also measured, and they included soil heat conduction measured at multiple locations at a depth of $0.04 \mathrm{~m}$ with heat flux sensors (model HFP01SC, Hukseflux Thermal Sensors, Delft, The Netherlands); soil temperature measured at triplicate locations each at depths of $0.02,0.04,0.08,0.16,0.32,0.64$, and $1.28 \mathrm{~m}$ with thermistor probes (model YSI44034, Therm-X, Hayward, CA); soil volumetric water content at depths of $0.05,0.10,0.20,0.50$, and $1.00 \mathrm{~m}$ with soil moisture probes (model Stevens Hydra Probe II, Stevens, Portland, OR). The continuous flux and meteorological measurements were sampled at $10 \mathrm{~Hz}$ and averaged over $30-\mathrm{min}$.

Measurements of the annual leaf litter accumulation on the forest floor during fall seasons were made manually in the vicinity of the flux tower. This annual leaf litter and the water content of the leaf litter residue were the only residue measurements that were made in this study; Table 1 provides a list of residue factors that were taken from the literature and used in this paper. Over 20 wire mesh baskets were placed randomly apart on the forest floor since 2006 and in subsequent years. The baskets stayed on the forest floor throughout the year so that the residue inside the baskets was subjected to natural changes, including wetting, drying, and decomposition that characterized the forest floor. Leaving the baskets on the forest floor also allowed leaf litter to accumulate in them from the successive fall senescence. The gravimetric water content of the residue baskets was measured occasionally and airdried litter samples indicated that the annual leaf litter production was about $550 \mathrm{~g} \mathrm{~m}^{-2}$. The thickness of undecomposed leaf residues on the forest floor was measured to be about $0.04 \mathrm{~m}$ overlying a humus layer about $0.06 \mathrm{~m}$ thick.

\section{Results and discussion}

Flux tower measurements over the growing seasons in 2006-2009 were used to evaluate the performance of the land-atmosphere, one-dimensional ALEX model in predicting energy budget components and $\mathrm{CO}_{2}$ fluxes of a deciduous forest that produced about $550 \mathrm{~g} \mathrm{~m}^{-2}$ of leaf litter residues each fall season. Due to the slow residue decomposition (Hanson et al., 2003a), about $0.04 \mathrm{~m}$ undecomposed residue persisted on the forest floor, which dramatically influenced the relative contribution of the forest floor to the forest energy budget and $\mathrm{CO}_{2}$ fluxes. Hanson et al. (2003b) studied leaf litter decomposition on the forest floor and found that only about $45 \%$ of the annual leaf litter was decomposed after a year, so that the soil surface below the forest was 


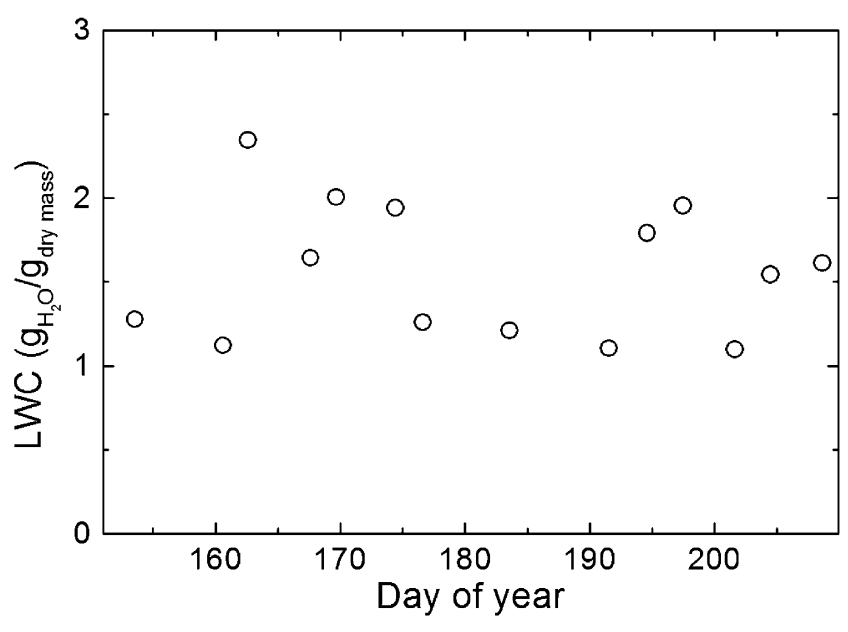

Fig. 2. Daily gravimetric water content of leaf litter residue below the deciduous forest measured during 2009. The maximum water content during well-drained wet residue conditions was around $2.5 \mathrm{gg}^{-1}$.

nearly shielded by leaf litter residues throughout the year. In this study, measurements of the gravimetric water content of the leaf litter residue during 2009 indicated a large scatter with maximum values of about $2.5 \mathrm{~g} \mathrm{~g}^{-1}$ for well-drained leaf litter residue conditions (Fig. 2). Bristow et al. (1986) used $4 \mathrm{gg}^{-1}$ as an appropriate model input value for the saturated gravimetric water content of the leaf litter residue. In previous studies below the forest in this study, maximum values of about $3 \mathrm{~g} \mathrm{~g}^{-1}$ were reported for gravimetric water content of the leaf litter residue (Hanson et al., 2003b; Wilson et al., 2000).

The daily LAI during 2006-2009 was a key input for the model and was successfully calculated based on measurements of the radiation fluxes above the forest (Wilson and Meyers, 2007). Values of LAI showed a strong variation during the course of the year from minimum values ranging from 1 to 1.5 for the woody biomass in winter and early spring that increased rapidly to maximum values ranging from 5 to 5.5 in early summer, and then decreased gradually after mid-summer before decreasing steadily during the end of fall as the forest shed its leaves (Fig. 3). Interestingly, values of LAI during the 2007 growing season were less than the other years, as peak LAI values were reached much later in the summer. The lower LAI values in 2007 were attributed to growing conditions in the spring that were appreciably different from the other years. A major

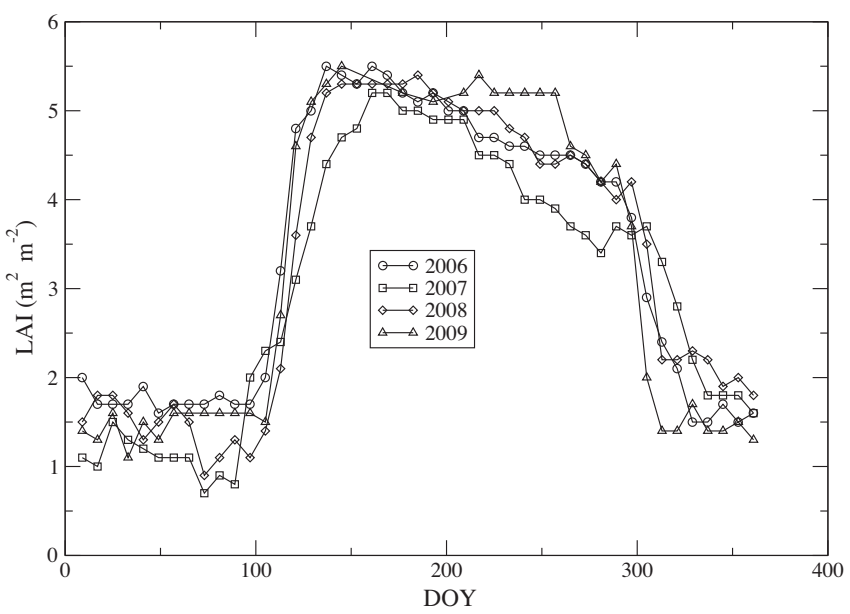

Fig. 3. Daily LAI of the deciduous oak forest at Chestnut Ridge, Oak Ridge, TN during 2006-2009 estimated based on flux tower measurements of PAR and global solar radiation above the canopy. freeze that occurred across the region during the first week in April 2007 caused severe damage to the emerging leaves of the forest canopy. While the forest managed to overcome the freeze damage, the extreme weather event disrupted the normal leaf emergence and slowed leaf development in ways that ultimately produced lower LAI values in 2007 than in other years.

\subsection{Field measurements}

Measurements of net radiation (RN), latent heat (LE), sensible heat $(\mathrm{H})$ and $\mathrm{CO}_{2}$ fluxes above the forest canopy and heat conduction $(G)$ at the soil surface below the forest during spring, summer and fall seasons in 2006 and 2009 are shown in Figs. 4-6. Spurious and missing data were elimated from the evaluation. During the daytime period, which was when values of the solar radiation were greater that zero, $\mathrm{RN}$ values were high during the spring and summer, reaching about $17 \mathrm{JM} \mathrm{m}^{-2} \mathrm{day}^{-1}$. They became low during the fall with values of about $10 \mathrm{MJ} \mathrm{m}^{-2}$ day $^{-1}$. Hourly midday values of RN averaged about $700 \mathrm{~W} \mathrm{~m}^{-2}$ during spring and summer and $400 \mathrm{~W} \mathrm{~m}^{-2}$ during fall. This seasonal variation in $\mathrm{RN}$ was typical of values reported by Wilson and Baldocchi (2000). High values of RN above the canopy during both spring leafless and summer fully leafed periods suggested that the variation in LAI had a much greater effect on the radiation transmitted below the canopy than on RN above the canopy. As expected, the dense summertime LAI reduced the radiation transmitted to the understory and the high incidence of radiation and low reflectivity of the canopy resulted in high RN above the canopy. The forest was characterized by a high density of woody biomass and litter residue cover that have nearly identical reflectivity, absorptivity and emissivity as the canopy; thus, the high RN above the canopy during low LAI periods resulted from the relatively large increase in radiation absorbed by the woody biomass and litter residue.

Measurements of the relative contribution of RN-G indicated seasonal variation, with daytime values of $\mathrm{G}$ about $8 \%$ of $\mathrm{RN}$ during the spring leafless period compared with $3 \%$ during the summer. The forest-floor RN-G, latent heat, and sensible heat fluxes were not measured in this study because the objective of this study was to evaluate the impact of litter residue cover on the net ecosystem energy and $\mathrm{CO}_{2}$ fluxes. Compared with above-canopy measurements, direct measurements of energy balance components below the vegetation are relatively scarce and have mostly involved shortterm studies (Sauer et al., 1995; Denmead and Bradley, 1985, 1987; Baldocchi and Meyers, 1991; Baldocchi and Vogel, 1996). However, a few studies have evaluated the seasonal variation in radiation transfer and energy balance fluxes below vegetation (Baldocchi et al., 1986, 2000; Wilson et al., 2000). For example, Wilson et al. (2000) reported direct measurements of the energy balance at the forest floor over an annual cycle. They measured the seasonal variation in $\mathrm{G}, \mathrm{RN}$, and $\mathrm{H}$, with higher understory fluxes during the spring and lower understory fluxes during the summer. By contrast, they found that latent heat at the forest floor responded more to changes in litter residue water content than to seasonal changes in RN and LAI.

One important difference between the seasonal variations of the above-canopy $\mathrm{H}$ and LE was due to differences in the relative contributions to $\mathrm{H}$ and LE from below the canopy. Wilson et al. (2000) reported that values of $\mathrm{H}$ at the forest floor increased to about $60-70 \%$ of values above the canopy during spring, and then decreased to about $6 \%$ during the summer growing season, while values of latent heat at the forest floor were consistently low with daily total values about $0.5 \mathrm{MJ} \mathrm{m}^{-2}$. They also found that values of the forest floor latent heat were about $56 \%$ of the total LE during the spring leafless period, when LE was dominated by the evaporation of water intercepted by the woody biomass and litter, and latent heat from the forest floor was about $8 \%$ of the total LE during 


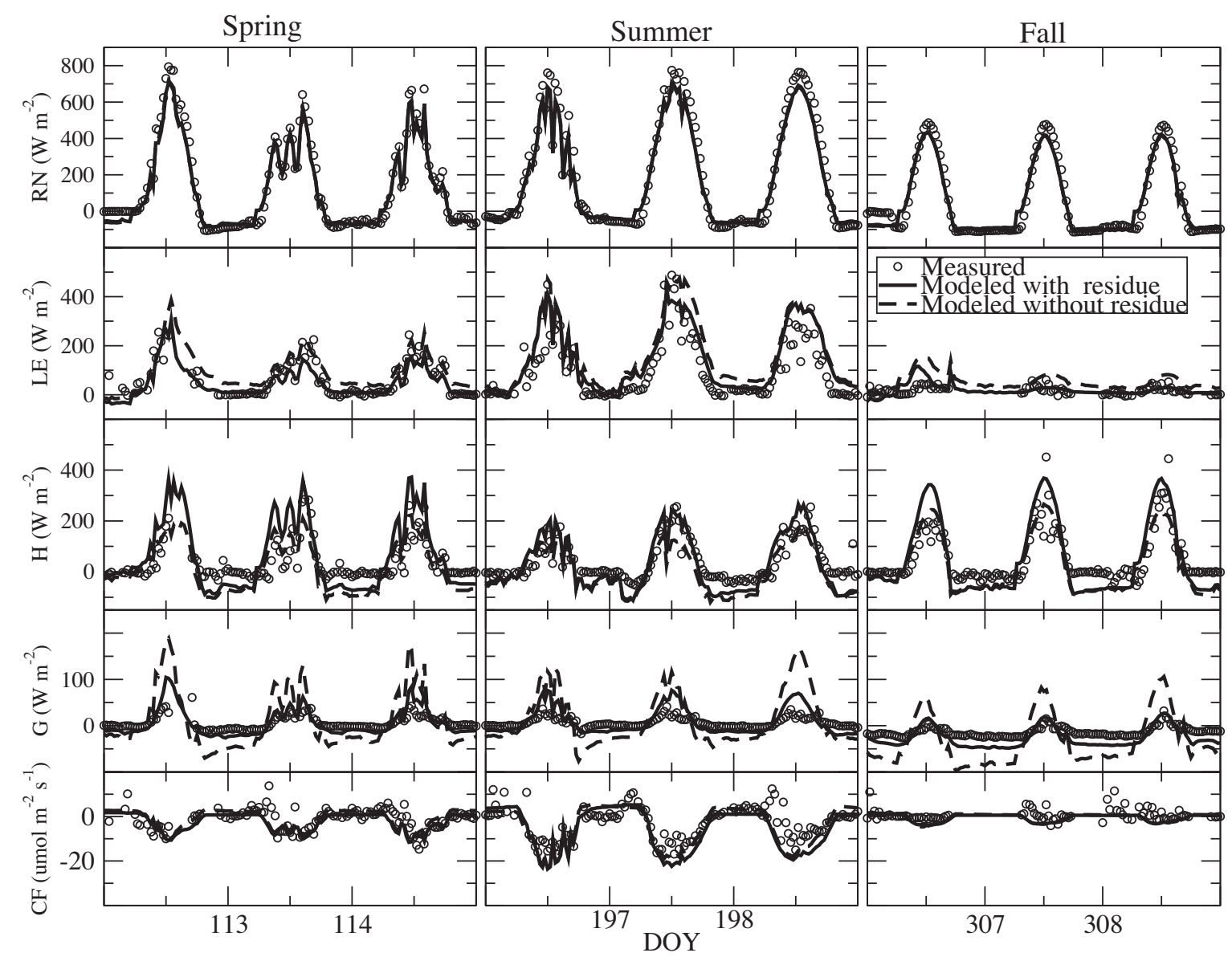

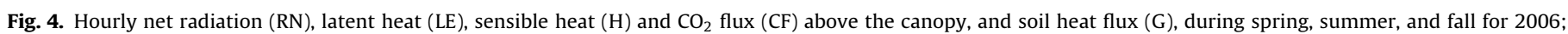
measurements (open circles) are compared with values modeled with residue (solid line) and without residue (dash line).

the summer growing season. In this study the Bowen ratio (H/LE) decreased from high values of greater than 6 during the winter and spring to about 0.5 during the summer (Fig. 7). This seasonal variation in the energy budget partitioning was typical for other deciduous forest sites (Turnipseed et al., 2002; Oliphant et al., 2004; Wilson et al., 2000; Wilson and Baldocchi, 2000).

The seasonal pattern in the daytime $\mathrm{CO}_{2}$ flux above the forest was similar to previous studies in the same forest (Wilson and Baldocchi, 2001). The general variation in the $\mathrm{CO}_{2}$ flux followed the change in LE more closely than that of RN, and was much different than the seasonal pattern of $\mathrm{H}$, indicating that the canopy resistance controlling $\mathrm{LE}$ also controlled the $\mathrm{CO}_{2}$ flux. Wilson and Baldocchi (2001) revealed that the total daytime $\mathrm{CO}_{2}$ flux above this forest in 1997 peaked to values of about $-0.7 \mathrm{~mol} \mathrm{~m}^{-2}$ during early summer, which was also when the peak LAI occurred. These high values gradually decreased to near-zero during the fall, when the forest was dominated by the leafless biomass of stems and branches. They also observed a similar pattern for the soil respiration beneath the forest, with daytime totals near zero during early spring and fall and about $-0.25 \mathrm{~mol} \mathrm{~m}^{-2}$ during the mid-summer period. In our study the mean total ecosystem daytime $\mathrm{CO}_{2}$ flux values over the forest from 2006 to 2009 peaked at about $-0.6 \mathrm{~mol} \mathrm{~m}^{-2}$ during the summer, with midday hourly values of about $-25 \mu \mathrm{mol} \mathrm{m}^{-2} \mathrm{~s}^{-1}$. These values were similar to the values observed by Wilson and Baldocchi (2001). The success of eddy covariance $\mathrm{CO}_{2}$ flux measurements is closely related to the accuracy of the energy budget closure measurement, as factors such as turbulence, vapor pressure deficit, radiation and soil water conditions that influence energy partitioning into $\mathrm{H}$ and $\mathrm{LE}$ can have similar effects on the $\mathrm{CO}_{2}$ flux (Twine et al., 2000). In our study, the energy balance closure was about $75-85 \%$ (Fig. 7), with a resultant lack of closure of about $15-25 \%$ indicating a possible underestimation of the $\mathrm{CO}_{2}$ flux above the forest.

Measurements of the soil water content at $0.1 \mathrm{~m}$ showed negligible hour-to-hour variations with sharp day-to-day variations closely connected to rainfall events (Figs. 8 and 9). The relatively high frequency of daily rainfall in 2009 resulted in less daily variability in the soil water content values, with soil water content values remaining above 0.2; however, in 2006 the water content decreased to about 0.1 . Unlike the soil water content, measurements of the soil temperature at $0.02 \mathrm{~m}$ showed clear diurnal and seasonal changes in 2006 and 2009, and daytime values increased gradually from spring to summer and then gradually fell during the fall (Figs. 8 and 9). The high rainfall conditions in 2009 resulted in relatively lower soil temperature values at $0.02 \mathrm{~m}$ than in 2006 . These values of soil temperature and water content were consistent with the energy budget components that have been measured below the forest by Wilson et al. (2000), who reported on the effect of litter residue water content on net radiation and latent heat at the forest floor, where strong seasonal variation in the net radiation and sensible heat fluxes influenced the seasonal variation in soil temperature.

\subsection{Model performance}

The comparison of modeling results to field measurements demonstrated the ability of ALEX to simulate observed vertical fluxes of energy, water and $\mathrm{CO}_{2}$ in the deciduous forest (Figs. 4-6. 


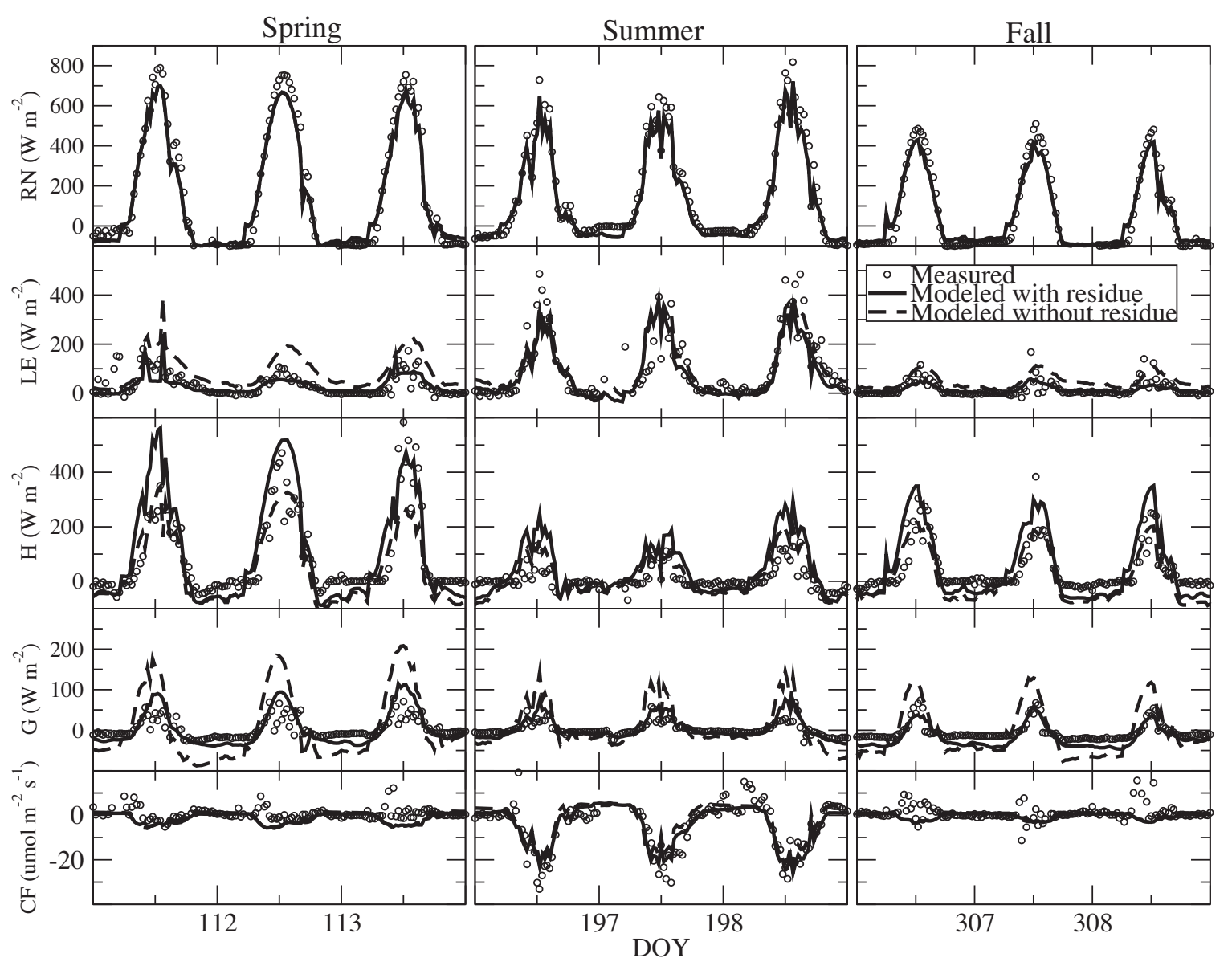

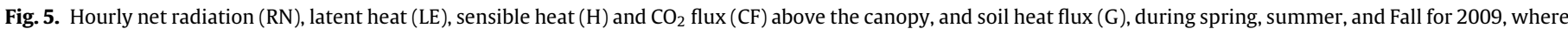
measurements (open circle) are compared to values modeled with residue (solid line) and without residue (dash line).

The model performed very well in simulating RN above the canopy, even though the model underestimated daytime values of RN by about $10 \%$ (Figs. 4 and 5). The RN deficit was most evident around midday hours. This discrepancy may have resulted from the radiation transfer parameters used by the model to calculate RN within and above the canopy. The ALEX model used leaf angle distribution, leaf absorptivity, and soil reflectance parameters whose values were fixed throughout the growing season. Thus, despite important advances in determining radiation transfer in vegetation canopies (Chen et al., 1997; Chen and Cihlar, 1995b; Miller and Norman, 1971), further work is still needed to evaluate the implications of seasonal changes in vegetation canopy and soil surface characteristics on the ALEX radiation transfer determination.

Simulated values of $\mathrm{LE}$ and $\mathrm{CO}_{2}$ fluxes above the canopy were in good agreement with eddy covariance measurements for the mean daytime totals, but on hourly time scales modeled values were slightly low during the summer. In particular, the model slightly underpredicted midday values of $\mathrm{LE}$ and $\mathrm{CO}_{2}$. It is difficult to identify the specific reasons for this problem; however ALEX assumed a constant seasonal averaged parameter of LUE to determine LE above the canopy, which is species-specific, and may actually vary during the growing season depending on environmental and canopy physiological stress factors that interact to constrain photosynthetic processes. These factors include temperature, soil moisture, soil nutrients, vapor pressure deficit, photosynthetically active radiation (PAR), and phenology (Anderson et al., 2000; Norman and Arkebauer, 1991; Runyon et al., 1994; Houborg et al., 2009). In addition, turbulent transfer parameters used by ALEX to formulate mass and energy transfer at the soil surface and in the residue layer below the canopy were based on work in crop environments (Bristow et al., 1986; Sauer et al., 1995). The deciduous forest environment in this study was much more complex than the uniform environments found in most crops. The forest canopy was dominated by multiple species of oaks, and the forest floor was highly heterogeneous not only in the physical properties of the soil, residue and landscape, but also in radiation fluxes and the turbulent fluxes of energy and $\mathrm{CO}_{2}$ (Wilson and Meyers, 2001; Wilson et al., 2000)

Modeled values of $\mathrm{H}$ above the canopy were in reasonable agreement with eddy covariance measurements, but less so for $\mathrm{H}$ than for $\mathrm{LE}$ and $\mathrm{CO}_{2}$ fluxes. For example, on hourly time scales (Figs. 4 and 5), the discrepancies between modeled and measured values of $\mathrm{H}$ was larger during the spring than during the summer and fall. The model tended to overpredict $G$ below the forest throughout the growing season, which may have resulted from shortcomings in the formulation of the available energy and the partitioning of energy into $\mathrm{H}$ and latent heat below the forest canopy. A similar disagreement was reported for $\mathrm{H}$ and $\mathrm{G}$ in an evaluation of ALEX in this forest (Anderson et al., 2000). One important shortcoming of the ALEX model, in addition to the consideration of residue effects, is an implicit use of K-theory to describe the turbulent transport of $\mathrm{H}$ and water vapor below the canopy. Field and modeling studies have reported measurements of countergradient fluxes of heat, water vapor and $\mathrm{CO}_{2}$ within forest canopies (Raupach, 1989; Denmead et al., 2000). Although vertical profiles of scalar transport within the canopy were unavailable in this study, in detailed measurements of energy budget partitioning below 


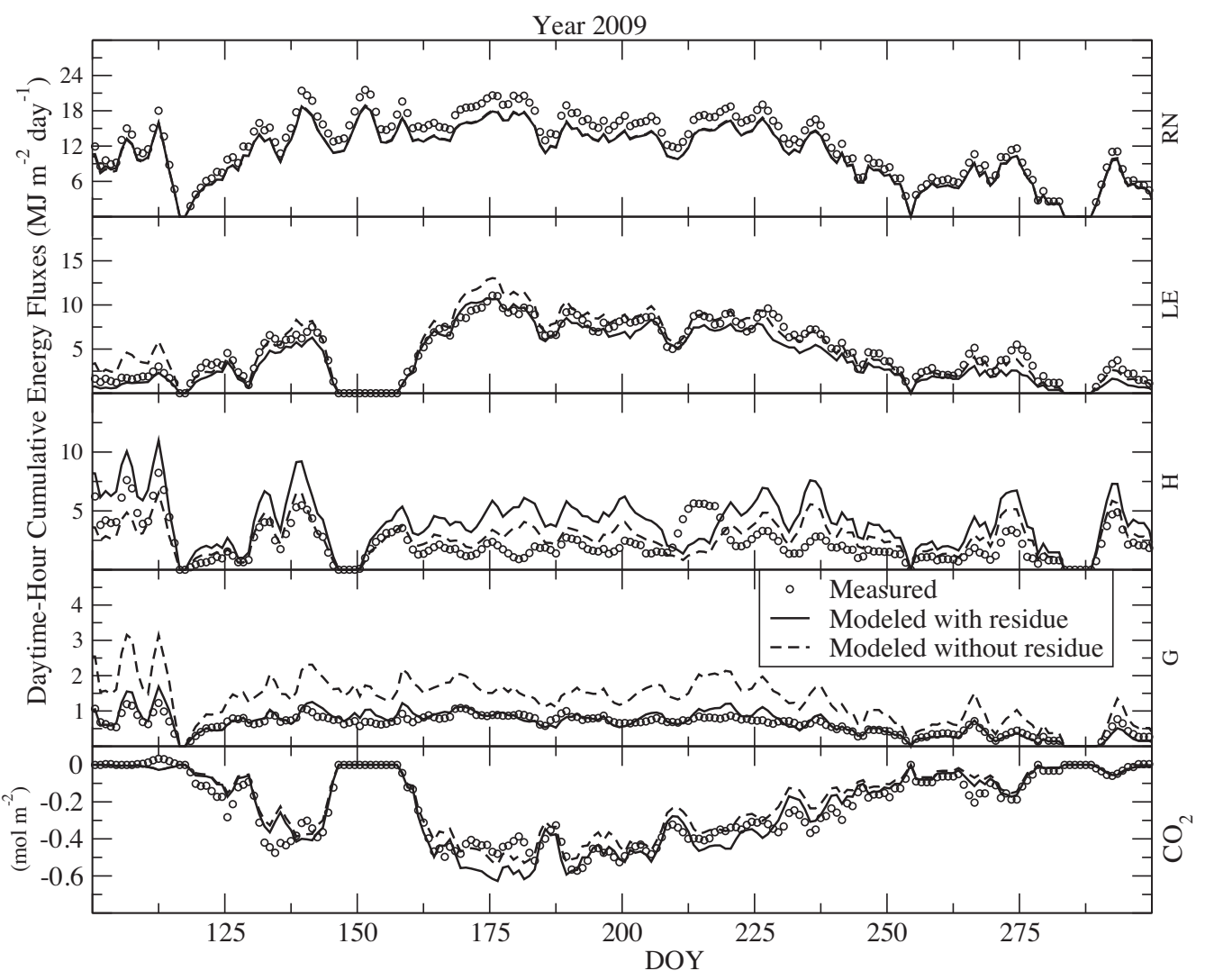

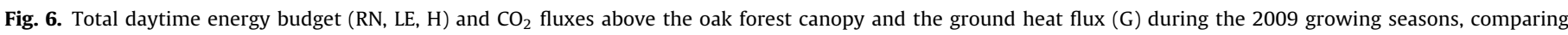
measurements (open circles) with values modeled with residue (solid line) and without residue (dash line); and data were missing around DOY 150 and 290.

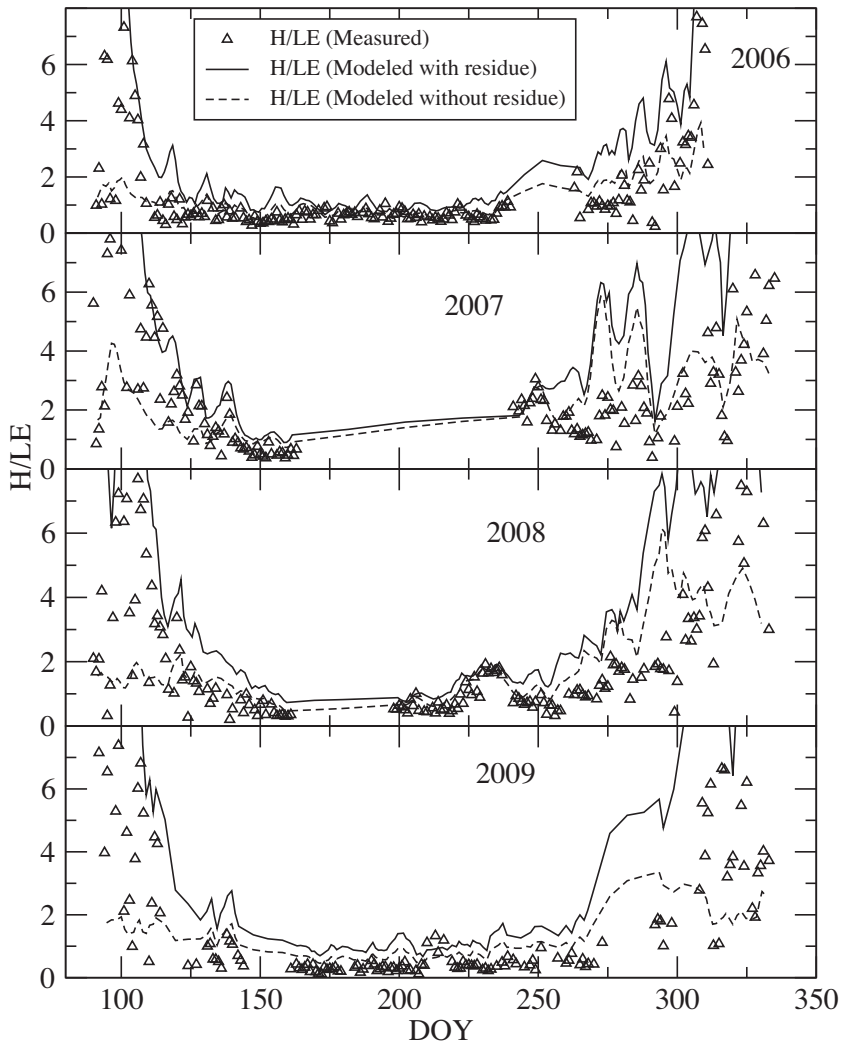

Fig. 7. Mid-daytime averaged energy budget balance (stars) and Bowen ratio values measured (triangle) and modeled with residue (open circles) and without residue (open square) during 2006-2009; data were missing around DOY 240-260 in 2006, $160-240$ in 2007, 160-195 in 2008, and 145-160 in 2009. the forest relative to the above-canopy energy budget, Wilson et al. (2000) suggested that the seasonality of the forest canopy affected $\mathrm{H}$ and $\mathrm{G}$ below the canopy more than the LE from the forest floor, and they revealed that LE below the forest was strongly coupled to changes in the vapor pressure deficit (VPD) and surface conductance above the canopy. Another area where future work on the ALEX within-canopy transfer processes is needed is in separating the leaf portion of the canopy from tree stems and branches. The current ALEX model does not explicitly include stems and branches, which form a large portion of deciduous forest canopies. Instead, the canopy in ALEX is described through the prescribed bulk LAI divided between green and dead area fractions. This omission of the effects of forest stems and branches may cause errors in the storage of heat and water within the canopy (Oliphant et al., 2004), especially during spring and fall when the canopy is dominated by woody biomass. Unlike photosynthetically active leaves that absorb radiation during $\mathrm{CO}_{2}$ assimilation and are cooled by transpiration, the woody biomass of the forest not only does not transpire, but it also absorbs radiation that is either stored or re-emitted as heat flux. Furthermore, the environment within the forest may have been characterized by spatial heterogeneity in the wind speed and in the fluxes of radiation, heat, water, and $\mathrm{CO}_{2}$ (Wilson et al., 2000). Single-point eddy covariance measurements and the onedimensional ALEX model consider the soil-plant-atmosphere as a horizontally homogeneous medium. Therefore the ALEX model performance can be further improved as issues of field measurements and model formulations are resolved under a wide range of soil-vegetation-environment conditions.

This study showed that it is important to consider the presence of litter residues in modeling energy and mass transport in forest environments. Percent differences between the ALEX model without residue effects and measurements of fluxes in grasslands in Kansas and Oklahoma, corn and soybean crops 
(a) Hourly time-series for a two-week period during summer in 2006

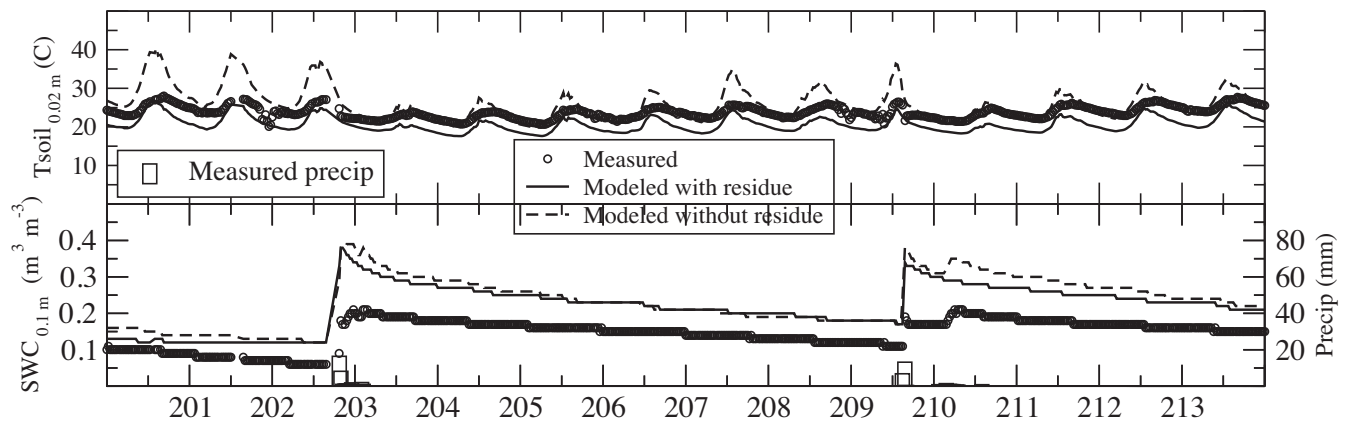

(b) Daily time-series from spring-fall in 2006

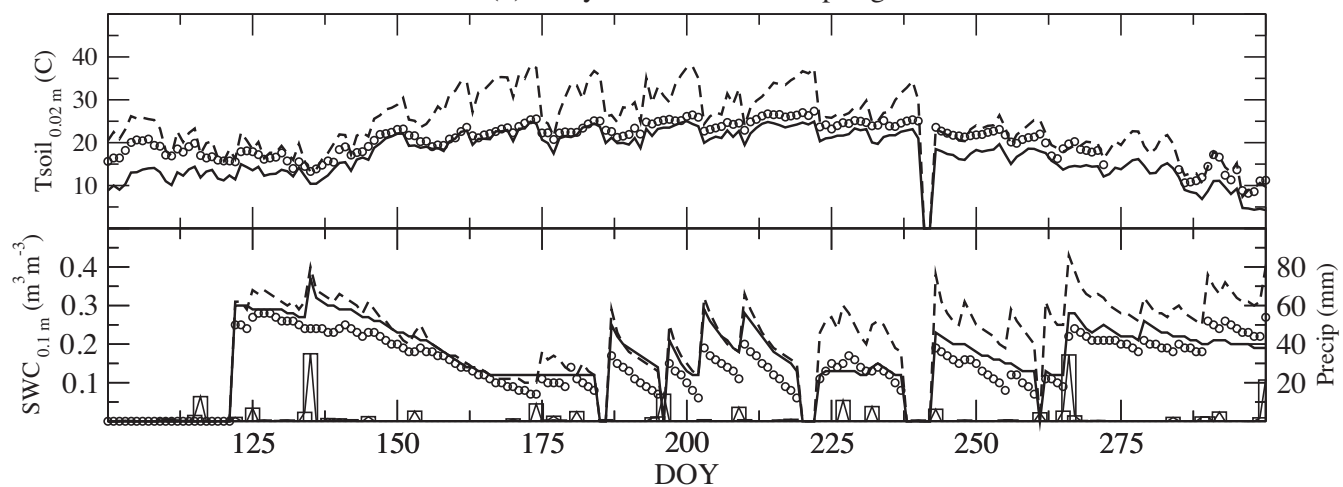

Fig. 8. Hourly (a) and daily (b) soil temperature ( $\left.T_{\text {soil }}\right)$ at $0.02 \mathrm{~m}$, soil volumetric water content (SWC) within $0.1 \mathrm{~m}$ of top soil surface, and total precipitation above the canopy during the 2006 growing seasons. Measurements consist of open circles and bars; the solid lines show values modeled with residue cover; and the dash lines were modeled without residue cover; zero values of SWC and $T_{\text {soil }}$ indicate missing data.

(a) Hourly time-series for a two-week period during summer in 2009

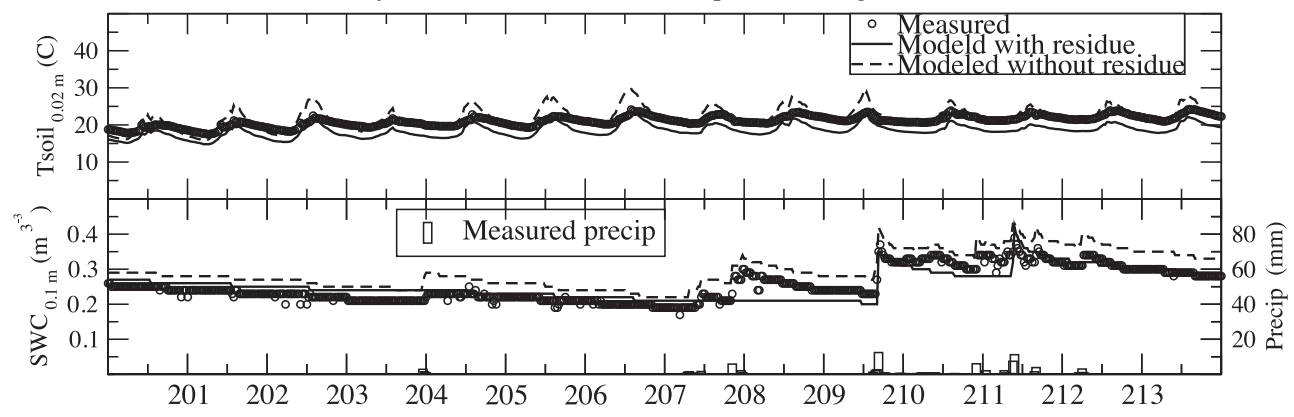

(b) Daily time-series from spring-fall in 2009

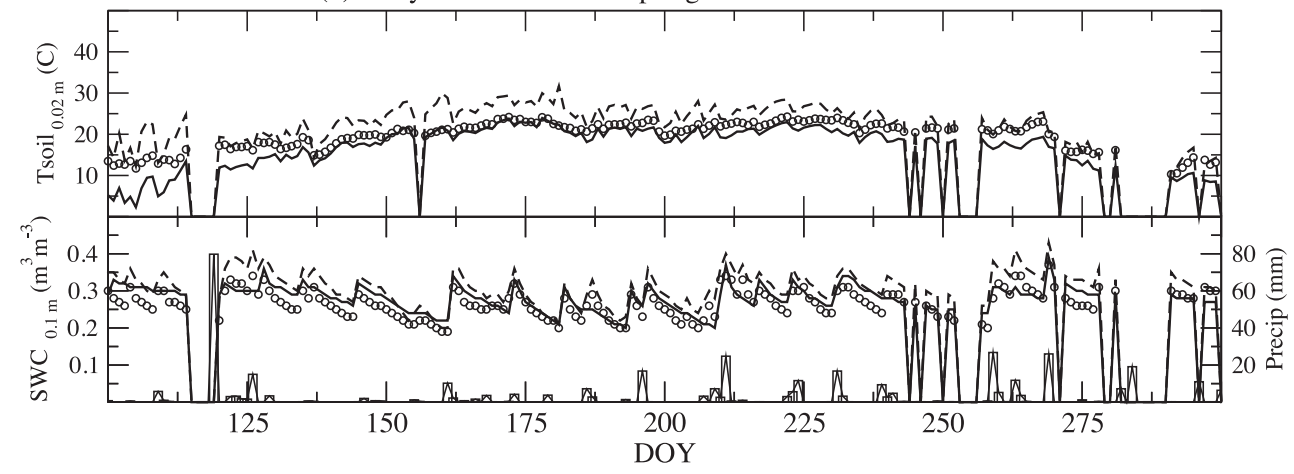

Fig. 9. Hourly (a) and daily (b) soil temperature ( $\left.T_{\text {soil }}\right)$ at $0.02 \mathrm{~m}$, soil volumetric water content (SWC) within $0.1 \mathrm{~m}$ of top soil surface, and total precipitation above the canopy during the 2009 growing seasons. Measurements consist of open circles and bars; the solid lines show values modeled with residue cover; and the dash lines were modeled without residue cover; zero values of SWC and $T_{\text {soil }}$ indicate missing data. 


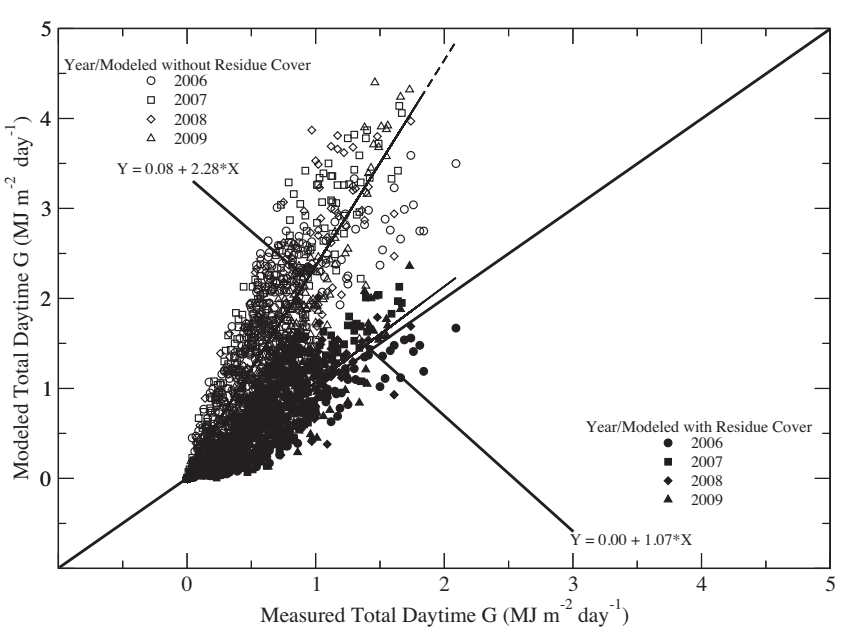

Fig. 10. Measured and modeled total daytime ground heat flux at the forest floor during the course of the growing season for 2006-2009. Values modeled with residue cover (filled symbols) agreed much better with measurements than the modeled without residue cover (open symbols).

in Illinois, desert shrubs in southern Arizona, and Black spruce in the boreal forest in Canada were found to be $138 \%$ for $\mathrm{H}$, $24 \%$ for $\mathrm{LE}$ and $33 \%$ for $\mathrm{CO}_{2}$ and $279 \%$ for $\mathrm{G}$ (Anderson et al., 2000).

Inclusion of an explicit formulation of a residue layer on the soil surface in the ALEX model in this study improved the simulation of the energy, water and $\mathrm{CO}_{2}$ exchange in a deciduous forest (Table 2). The biggest improvement was made in the simulation of $\mathrm{G}$ below the canopy and $\mathrm{H}$ above the canopy, particularly during the spring and fall seasons. Overprediction of daytime $G$ was substantially reduced, with the slope of the linear regression between predicted and measured values reduced from 2.28 for the original ALEX model without residue effects to 1.07 with residue effects (Fig. 10). Under-prediction of $\mathrm{H}$ was also improved, as the slope of the regression line between predicted and measured values was increased from 0.69 for the original ALEX model without residue effects to 1.16 for the modified ALEX model (Fig. 11). The modification of residue effects showed a clear improvement in modeling LE above the canopy during the spring and fall, but this improvement was less evident during the summer season. The regression line between predicted and measured daytime LE yielded significant

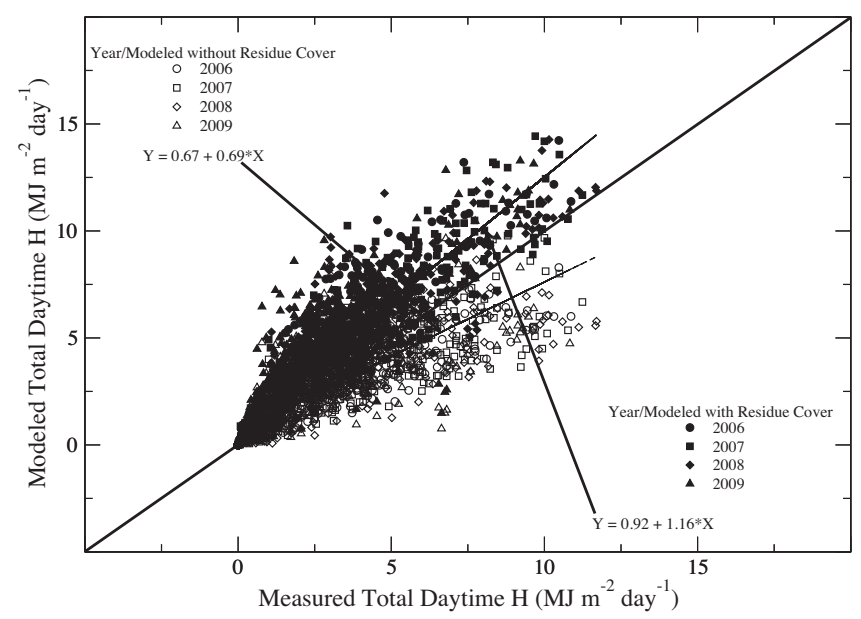

Fig. 11. Measured and modeled total daytime sensible heat flux above the oak forest canopy during the course of the growing season for 2006-2009. Values modeled with residue cover (filled symbols) agreed with the measurements much more closely than with modeled without residue cover (open symbols).

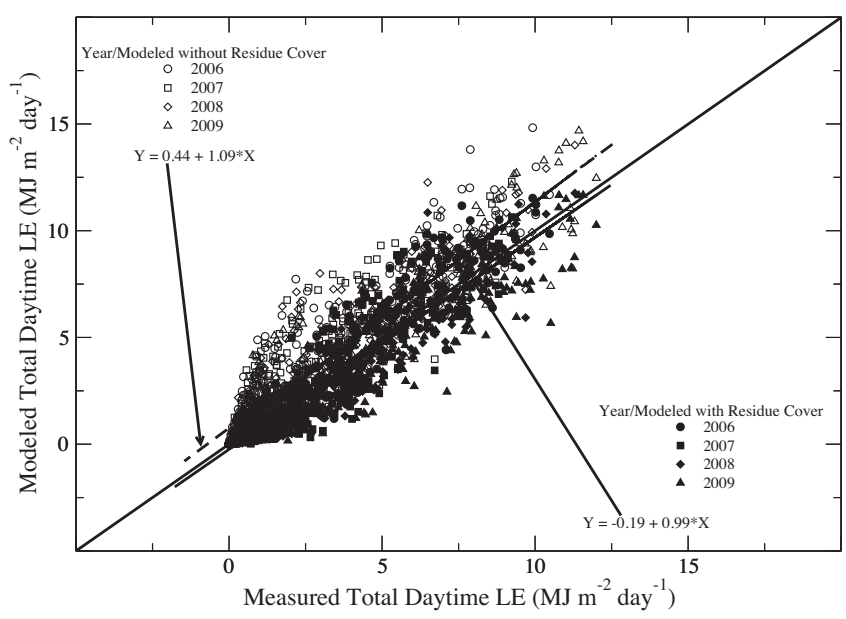

Fig. 12. Measured and modeled daytime daily cumulative latent heat flux above the oak forest canopy during the course of the growing season for 2006-2009. Values modeled with residue cover (filled symbols) agreed much better with measurements than modeled without residue cover (open symbols).

scatter with a slope of about 1.0 for both model versions (Fig. 12). However, without the modification of residue effects, the model significantly underpredicted LE during the spring and fall, which coincided with large overprediction of $G$ and underprediction of $\mathrm{H}$ (Figs. 4-6). Consistent with the improvement in model performance in predicting the energy balance, the modification of residue effects showed slight improvement in predicting the $\mathrm{CO}_{2}$ flux over the canopy. Even though the regression between the predicted and measured daytime total $\mathrm{CO}_{2}$ flux showed large scatter, inclusion of residue effects improved the slope from 0.89 to 1.02 (Fig. 13). As with the energy and $\mathrm{CO}_{2}$ fluxes, the omission of residue effects resulted in substantial over-prediction of daytime soil temperature at $0.02 \mathrm{~m}$, but only a slight over-prediction of the soil water content at $0.1 \mathrm{~m}$ depth (Figs. 8 and 9). Another important effect of the surface residue on $\mathrm{CO}_{2}$ fluxes in deciduous forests are respiration pulses caused by residue wetting and drying cycles connected with rain events as reported in previous studies (Hanson et al., 2003a; Wilson et al., 2000). For the soil temperature, differences between predicted and measured values were as high as $9^{\circ} \mathrm{C}$ without residue effects, compared with $1^{\circ} \mathrm{C}$ when residue effects were considered in the model (Figs. 8 and 9). The importance of accounting for

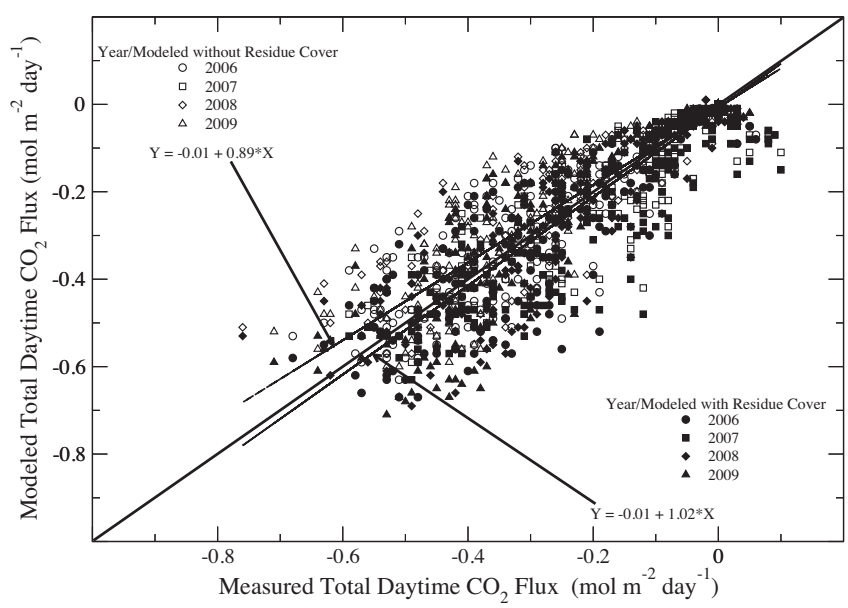

Fig. 13. Measured and modeled total daytime $\mathrm{CO}_{2}$ fluxes above the oak forest canopy during the course of the growing season for 2006-2009. Values modeled with residue cover (filled symbols) agreed much better with the measurements than with the modeled values without residue cover (open symbols). 
litter residues in modeling soil temperature under forests was also demonstrated by Paul et al. (2004). For the soil water content, the difference between the model prediction was relatively small, but this difference increased during low soil water content conditions, and predicted values were much higher when the model ignored the effects of residues. Similar residue effects on soil temperature and soil water content were also successfully simulated under short grasses (Grant et al., 1995)

\section{Conclusions}

This study has evaluated the exchange of energy and $\mathrm{CO}_{2}$ above and soil heat conduction below a deciduous forest during daytime conditions from the spring to fall growing season. The ALEX model demonstrated that the presence of residues on a deciduous forest floor can significantly affect the exchange of energy and mass in vegetation stands throughout the growing season. This study has extended the original ALEX model formulation as a simple, comprehensive model available for studying soil-plant-environment interactions in different vegetation systems. However, the discrepancy found between model simulations and field measurements suggests the need for further research that will involve simultaneous modeling-measurement efforts for both daytime and nighttime conditions within and above the vegetation canopy over all seasons of the year.

The ALEX model successfully simulated the hourly energy and $\mathrm{CO}_{2}$ exchange observed in the deciduous forest. The $\mathrm{H}$, $\mathrm{LE}$ and $\mathrm{CO}_{2}$ fluxes showed substantial daytime variations during the spring, summer, and fall growing seasons. The summer RN partitioning was mostly dominated by $\mathrm{LE}$ and less by $\mathrm{H}$ and $\mathrm{G}$ due to the increased magnitude of transpiration. During spring and fall, LE was greatly reduced as transpiration diminished, and the increased importance of $\mathrm{H}$ during the spring and fall was due to the leaflessness that allowed increased radiation to penetrate into the forest, exposing the woody biomass and litter residues to significant heating. The omission of a residue layer at the forest floor caused large discrepancies in the model simulation of $\mathrm{H}, \mathrm{LE}$ and $\mathrm{G}$ during the spring and fall. The biggest improvement was made in the simulation of sensible heat and soil heat conduction when residue effects were explicitly considered in the ALEX model. The strong decrease of $G$ results from the fact that the thermal conductivities of the residue cover are much lower than the soil beneath. This difference in the thermal property limits the heat transfer between the soil and the air layer immediately above the residue, an interaction that also reduces vapor transfer and ultimately soil evaporation. While the residue provides a resistance to heat and vapor transfer between the soil and air above the residue, the large values of $\mathrm{H}$ during the spring and fall, when strong solar radiation penetrates into the open forest, indicate that the residue may have increased mixing and enhanced turbulent exchange between the forest floor and the forest canopy. The contribution of soil respiration to the $\mathrm{CO}_{2}$ flux seems to depend not only on the biophysical controls of the residue but also on the residue wetting and drying cycles connected with rain events. The successful evaluation of the residue modification of the model in this study provides evidence that many of the residue cover and soil factors that interact with each other can be integrated in a simple, analytical land-atmosphere energy exchange model to study the transfer of energy and mass to and from plant canopies and the underlying soil. Results of this study have demonstrated that ALEX is quite useful for quantifying the transfer of energy and mass below and above plant canopies. One important limitation of the ALEX model is that the soil-plant-atmosphere system is treated as a horizontally homogeneous medium. This assumption requires further work to consider the influence of heterogeneity on the soil surface characteristics, wind speed, energy and moisture and their impact on the vegetation. Future modeling work should involve long-term measurements of microclimate factors within and above vegetation canopies that include mass and energy transport within the residue-soil system. An essential part of improving measurements within the canopy would be to monitor water and energy transport within the residue layer remotely to relieve the burden of on-site measurements. In addition, while rapid advances in eddy covariance instrumentation have led to flux tower networks that perform increasingly well in different vegetation environments, considerable effort is still required to maintain, process, and provide high quality long-term measurements of energy, water and $\mathrm{CO}_{2}$ fluxes in these different vegetation environments.

\section{Acknowledgement}

This work was funded by the NOAA OAR/ARL Climate Research Program.

\section{References}

Aase, J., Siddoway, F., 1980. Stubble height effects on seasonal microclimate, water balance, and plant development of no-till winter wheat. Agric. Forest Meteorol. $21,1-20$.

Aiken, R., Flerchinger, G., Farahani, H., Johnsen, K., 1997. Energy balance simulation for surface soil and residue temperatures with incomplete cover. Agron. J. 89, 404-415.

Anderson, M., Kustas, W., Norman, J., 2003. Upscaling and downscaling-a regional view of the soil-plant-atmosphere continuum. Agron. J 95, 1408-1423.

Anderson, M., Norman, J., Meyers, T., Diak, G., 2000. An analytical model for estimating canopy transpiration and carbon assimilation fluxes based on canopy light use efficiency. Agric. Forest Meteorol. 101, 265-289.

Arain, M., Black, T., Barr, A., Griffis, T., Morgenstern, K., Nesic, Z., 2003. Year-round observations of the energy and water vapour fluxes above a boreal black spruce forest. Hydrol. Proc. 17, 3581-3600.

Baker III, T., Lockaby, B., Conner, W., Meier, C., Stanturf, J., Burke, M., 2001. Leaf litter decomposition and nutrient dynamics in four southern forested floodplain communities. Soil Sci. Soc. Am. J. 65, 1334-1347.

Baldocchi, D., Hutchison, B., Matt, D., McMillen, R., 1986. Seasonal variation in the statistics of photosynthetically active radiation penetration in an oak-hickory forest. Agric. Forest Meteorol 36, 343-361.

Baldocchi, D., Law, B., Anthoni, P., 2000. On measuring and modeling energy fluxes above the floor of a homogeneous and heterogeneous conifer forest. Agric. Forest Meteorol. 102, 187-206.

Baldocchi, D., Meyers, T., 1991. Trace gas exchange at the floor of a deciduous forest I. Evaporation and CO2 efflux. J. Geophys. Res. Atmos 96, 7271-7285.

Baldocchi, D., Vogel, C., 1996. A comparative study of water vapor, energy and CO2 flux densities above and below a temperate broadleaf and a boreal pine forest. Tree Physiol. 16, 5-16.

Baldocchi, D., Wilson, K., 2001. Modeling $\mathrm{CO}_{2}$ and water vapor exchange of a temperate broadleaved forest across hourly to decadal time scales. Eco. Model. 142 155-184.

Ball, J., Woodrow, I., Berry, J., 1987. Progress in Photosynthesis Research. Ch. A Model Predicting Stomatal Conductance and its Contribution to the Control of Photosynthesis Under Different Environmental Conditions. Nijhoff, Dodrecht, pp. 221-225.

Bristow, K., Campbell, G., Papendick, R., Elliott, L., 1986. Simulation of heat and moisture transfer through a surface residue-soil system. Agric. Forest Meteorol. 36, 193-214.

Burgess, M., Mehuys, G., Madramootoo, C., 2002. Nitrogen dynamics of decomposing corn residue components under three tillage systems. Soil Sci. Soc. Am. J. 66, 1350-1358.

Bussiere, F., Cellier, P., 1994. Modification of the soil temperature and water content regimes by a crop residue mulch: experiment and modelling. Agric. Forest Meteorol 68, 1-28.

Campbell, G., 1985. Soil Physics with BASIC: Transport Models for Soil-Plant Systems. Elsevier, New York.

Campbell, G., Norman, J., 1998. An Introduction to Environmental Biophysics. Springer-Verlag, New York.

Caprio, J., Grunwald, G., Snyder, R., 1985. Effect of standing stubble on soil water loss by evaporation. Agric. Forest Meteorol. 34, 129-144.

Chen, J., Blanken, P., Black, T., Guilbeault, M., Chen, S., 1997. Radiation regime and canopy architecture in a boreal aspen forest. Agric. Forest Meteorol. 86, 107-125.

Chen, J., Cihlar, J., 1995b. Plant canopy gap-size analysis theory for improving optical measurements of leaf-area index. Appl. Opt. 34, 6211-6222.

Chung, S., Horton, R., 1987. Soil heat and water flow with a partial surface mulch. Water Resour. Res. 23, 2175-2186.

Collatz, G., Ball, J., Grivet, C., Berry, J., 1991. Physiological and environmental regulation of stomatal conductance, photosynthesis and transpiration: a model that includes a laminar boundary layer. Agric. Forest Meteorol. 54, 107-136. 
Collatz, G., Ribas-Carbo, J., Berry, J., 1992. Coupled photosynthesis-stomatal conductance model for leaves of C4 plant. Aust J. Plant Physiol 19, 519-538.

Daughtry, C., 2001. Discriminating crop residues from soil by shortwave infrared reflectance. Agron. J. 93, 125-131.

Denmead, O., Bradley, E., 1985. The Forest-Atmosphere Interaction. Ch. Fluxgradient relationship in a forest canopy. D. Reidel Publishers, Dordrecht, pp. 421-441.

Denmead, O., Bradley, E., 1987. On scalar transport in plant canopies. Irrig. Sci. 8, 131-149.

Denmead, O., Harper, L., Sharpe, R., 2000. Identifying sources and sinks of scalars in a corn canopy with inverse Lagrangian dispersion analysis, I. Heat. Agric. Forest Meteorol. 104, 67-73.

Dickinson, R., Henderson-Sellers, A., Kennedy, P., 1993. Biosphere Atmosphere Transfer Scheme (BATS) Version 1e as Coupled to the NCAR Community Climate Model. Tech. rep., NCAR Technical Note.

El Maayar, M., Price, D., Delire, C., Foley, J., Black, T., Bessemoulin, P., 2001. Validation of the integrated Biosphere Simulator over Canadian deciduous and coniferous boreal forest stands. J. Geophys. Res. 106, 14,339-14,355.

Enrique, G., Braud, I., Jean-Louis, T., Michel, V., Pierre, B., Jean-Christophe, C., 1999. Modelling heat and water exchanges of fallow land covered with plant-residue mulch. Agric. Forest Meteorol 97, 151-169.

Enz, J., Brun, L., Larsen, J., 1988. Evaporation and energy balance for bare and stubble covered soil. Agric. Forest Meteorol. 43, 59-70.

Farquhar, G., von Caemmerer, S., Berry, J., 1980. A biochemical model of phosynthetic $\mathrm{CO}_{2}$ assimilation in leaves of C3 species. Planta 149, 78-90.

Ferreira, L., Yoshioka, H., Huete, A., Sano, E., 2003. Seasonal landscape and spectral vegetation dynamics in the Brazilian Cerrado: An analysis within the Large-Scale Biosphere-Atmosphere Experiment in Amazonia (LBA). Remote Sens. Environ. $87,534-550$

Findeling, A., Garnier, P., Coppens, F., Lafolie, F., Recous, S., 2007. Modelling water, carbon and nitrogen dynamics in soil covered with decomposing mulch. Eur. J. Soil Sci. 58, 196-206.

Gijsman, A., Hoogenboom, G., Parton, W., Kerridge, P., 2002. Modifying DSSAT crop models for low-input agricultural systems using a soil organic matter-residue module from CENTURY. Agron. J 94, 462-474.

Gower, S., Kucharik, C., Norman, J., 1999. Direct and indirect estimation of leaf area index, fapar, and net primary production of terrestrial ecosystems. Remote Sens. Environ. 70, 29-51.

Grant, R., Izaurralde, R., Chanasyk, D., 1995. Soil temperature under different suface managements: testing a simulation model. Agric. Forest Meteorol. 73, 89-113.

Hanson, P., O’Neill, E., Chambers, M., Riggs, J., Joslin, J., Wolfe, M., 2003a. Ecological Studies: North American Temperate Deciduous Forest Responses to Changing Precipitation Regimes. Vol. 166, Ch. Soil respiration and litter decomposition. Springer, New York, pp. 163-189.

Hanson, P., Todd, D., Joslin, J., 2003b. Ecological Studies: North American Temperate Deciduous Forest Responses to Changing Precipitation Regimes. Vol. 166, Ch. Canopy Production. Springer, New York, pp. 303-315.

Houborg, R., Anderson, M., Norman, J., Wilson, T., Meyers, T., 2009. Intercomparison of a 'bottom-up' and 'top-down' modeling paradigm for estimating carbon and energy fluxes over a variety of vegetative regimes across the U.S. Agric. Forest Meteorol. 149 (11), 1875-1895.

Kongoli, C., Bland, W., 2000. Long-term snow depth simulations using a modified atmosphere-land exhange model. Agric. Forest Meteorol. 104, 273-287.

Kucharik, C., Brye, K., 2003. Integrated Blosphere Simulator (IBIS) yield and nitrate loss predictions for Wisconsin maize receiving varied amounts of nitrogen fertilizer. J. Environ. Quality 32, 247-268.

Kucharik, C., Twine, T., 2007. Residue, respiration, and residuals: evaluation of a dynamic agroecosystem model using eddy flux measurements and biometric data. Agric. Forest Meteorol. 146, 134-158.

Miller, E., Norman, J., 1971. A sunfleck theory for plant canopies. I. Lengths of sunlit segments along a transect. Agron. J. 63, 735-738.

Monteith, J., 1965. The state and Movement of Water in Living Organisms.

Norman, J., 1979. Modification of the Aerial Environment of Plants, Ch. Modeling the Complete Crop Canopy. ASAE, pp. 249-277.

Norman, J., 1982. Integrated Pest Management, Ch. Simulation of Microclimates. Academic Press, New York, pp. 65-99.

Norman, J., Arkebauer, T., 1991. Predicting canopy light-use efficiency from leaf characteristics. In: Modeling Plant and Soil Systems, Agronomy Monograph. No. 31. ASA-CSSA-SSSA, Madison, pp. 125-143.

Norman, J., Campbell, G., 1983. Advances in Irrigation. Ch. Application of a Plantenvironment Model to Problems in Irrigation. Academic Press, New York, pp. 156-188.

Norman, J., Garcia, R., Verma, S., 1992. Soil surface $\mathrm{CO}_{2}$ fluxes and the carbon budget of a grassland. J. Geophys. Res. 97 (D17), 18845-18853.
Norman, J., Kustas, W., Humes, K., 1995. Source approach for estimating soil and vegetation energy fluxes in observations of directional radiometric surface temperature. Agric. Forest Meteorol. 77, 263-293.

Novak, M., Chen, W., Orchansky, A., Ketler, R., 2000a. Turbulence exchange processes within and above a straw mulch. Part I: Mean wind speed and turbulence statistics. Agric. Forest Meteorol. 102, 139-154.

Novak, M., Chen, W., Orchansky, A., Ketler, R., 2000b. Turbulence exchange processes within and above a straw mulch. Part II: thermal and moisture regimes. Agric Forest Meteorol. 102, 155-171.

Ogee, J., Brunet, Y., 2002. A forest floor model for heat and moisture including a litter layer. J. Hydrol. 255, 212-233.

Oliphant, A., Grimmond, C., Zutter, H., Schimid, H., Su, H., Scott, S., Offerle, B., Randolph, J., Ehman, J., 2004. Heat storage and energy balance fluxes for a temperate deciduous forest. Agric. Forest Meteorol. 126, 185-201.

Paul, K., Polglase, P., Smethurst, P., O'Connell, A., Carlyle, C., Khanna, P., 2004. Soil temperature under forests: a simple model for predicting soil temperature under a range of forest types. Agric. Forest Meteorol. 121, 167-182.

Priestley, C., Taylor, R., 1972. On the assessment of surface heat flux and evaporation using large scale parameters. Monthly Weather Rev. (100), 81-92.

Raupach, M., 1989. Applying Langrangian fluid mechanics to infer scalar source distributions from concentration profiles in plant canopies. Agric. Forest Meteorol. 47, 85-108.

Runyon, J., Waring, R., Goward, S., Well, J., 1994. Environmental limits on net primary production and light-use efficiency across the Oregon transect. Ecol. Appl. 4, 226-237.

Sauer, J., Norman, J., Tanner, C., Wilson, T., 1995. Measurement of heat and vapor transfer coefficients at the soil surface beneath a maize canopy using source plates. Agric. Forest Meteorol. 75, 161-189.

Sauer, T., Hatfield, J., Prueger, J., 1996. Aerodynamic characteristics of standing corn subble. Agron. J. 88, 733-739.

Sauer, T., Hatfield, J., Prugger, J., Norman, J., 1998. Surface energy balance of a corn residue-covered field. Agric. Forest Meteorol. 89, 155-168.

Sauer, T., Norman, J., 1995. Simulated canopy microclimate using estimated below-canopy soil surface transfer coefficients. Agric. Forest Meteorol. 75, 135-160.

Shen, Y., Tanner, C., 1990. Radiative and conductive transport of heat through flailchopped corn residue. Soil Sci. Soc. Am. J 54, 653-658.

Shuttleworth, W., Wallace, J., 1985. Evaporation from sparse crops - An energy combination theory. Quart. J. Roy. Meteorol. 111, 839-855.

Tanner, C., Shen, Y., 1990. Water vapor transport through a flail-chopped corn residue. Soil Sci. Am. J. 54, 945-951.

Turnipseed, A., Blanken, P., Anderson, D., Monson, R., 2002. Energy budget above a high-elevation subalpine forest in complex topography. Agric. Forest Meteorol $110,177-201$.

Twine, T., Kustas, W., Norman, J., Cook, D., Houser, P., Meyers, T., Prueger, J., Starks, P., Wesely, M., 2000. Correcting eddy-covariance flux underestimates over a grassland. Agric. Forest Meteorol. 103 (3), 279-300.

Wagner-Riddle, C., Gillespie, T., Swanton, C., 1996. Rye mulch characterization for the purpose of microclimate modelling. Agric. Forest Meteorol. 78, 67-81.

Webb, E., Pearman, G., Leuning, R., 1980. Correction of flux measurements for density effects due to heat and water vapor transfer. Q. J. R. Meteorol. Soc. 106, $85-100$.

Wilson, K., Baldocchi, D., 2001. Comparing independent estimates of carbon dioxide exchange over 5 years at a deciduous forest in the southeastern United States. J. Geophys. Res. 106 (D24), 34,167-34,178.

Wilson, K., Hanson, P., Baldocchi, D., 2000. Factors controlling evaporation and energy partitioning beneath a deciduous forest over an annual cycle. Agric. Forest Meteorol. 102, 83-103.

Wilson, K., Hanson, P., Mulholland, P., Baldocchi, D., Wullschleger, S., 2001. A comparison of methods for determining forest evapotranspiration and its components: sap-flow, soil water budget, eddy covariance and catchment water balance. Agric. Forest Meteorol. 106, 153-168.

Wilson, K., Meyers, T., 2001. The spatial variability of energy and carbon dioxide fluxes at the floor of a deciduous forest. Boundary Layer Met. 98, 443-473.

Wilson, K.B., Baldocchi, D.D., 2000. Seasonal and interannual variability of energy fluxes over a broadleaved temperate deciduous forest in north america. Agric. Forest Meteorol. 100,1-18.

Wilson, T., Meyers, T., 2007. Determining vegetation indices from solar and photosynthetically active radiation fluxes. Agric. Forest Meteorol. 144, 160-179.

Wilson, T., Norman, J., Bland, W., Kucharik, C., 2003. Evaluation of the importance of Lagrangian canopy turbulence formulations in a soil-plant-atmosphere model. Agric. Forest. Meteorol. 115, 51-69.

Wu, Y., Perry, K., Ristaino, J., 1996. Estimating temperature of mulched and bare soil from meteorological data. Agric. Forest. Meteorol. 81, 299-323. 